Review Article

\title{
Mechanisms of Hydroxyurea-Induced Cellular Senescence: An Oxidative Stress Connection?
}

\author{
Sunčica Kapor $\mathbb{D}^{1},{ }^{1}$ Vladan Čokić $\mathbb{D},{ }^{2}$ and Juan F. Santibanez $\mathbb{D}^{2,3}$ \\ ${ }^{1}$ Department of Hematology, Clinical Hospital Center "Dr. Dragisa Misovic-Dedinje”, University of Belgrade, Serbia \\ ${ }^{2}$ Molecular Oncology Group, Institute for Medical Research, National Institute of Republic of Serbia, University of Belgrade, \\ Belgrade, Serbia \\ ${ }^{3}$ Centro Integrativo de Biología y Química Aplicada (CIBQA), Universidad Bernardo O’Higgins, Santiago, Chile
}

Correspondence should be addressed to Juan F. Santibanez; jfsantibanez@imi.bg.ac.rs

Received 6 May 2021; Revised 9 August 2021; Accepted 25 September 2021; Published 18 October 2021

Academic Editor: Amit Kumar Nayak

Copyright (C) 2021 Sunčica Kapor et al. This is an open access article distributed under the Creative Commons Attribution License, which permits unrestricted use, distribution, and reproduction in any medium, provided the original work is properly cited.

Hydroxyurea $(\mathrm{HU})$ is a water-soluble antiproliferative agent used for decades in neoplastic and nonneoplastic conditions. HU is considered an essential medicine because of its cytoreduction functions. HU is an antimetabolite that inhibits ribonucleotide reductase, which causes a depletion of the deoxyribonucleotide pool and dramatically reduces cell proliferation. The proliferation arrest, depending on drug concentration and exposure, may promote a cellular senescence phenotype associated with cancer cell therapy resistance and inflammation, influencing neighboring cell functions, immunosuppression, and potential cancer relapse. HU can induce cellular senescence in both healthy and transformed cells in vitro, in part, because of increased reactive oxygen species (ROS). Here, we analyze the main molecular mechanisms involved in cytotoxic/genotoxic HU function, the potential to increase intracellular ROS levels, and the principal features of cellular senescence induction. Understanding the mechanisms involved in HU's ability to induce cellular senescence may help to improve current chemotherapy strategies and control undesirable treatment effects in cancer patients and other diseases.

\section{Introduction}

Hydroxyurea (HU), also called hydroxycarbamide, is a simple hydroxylated compound with the molecular formula $\mathrm{CH}_{4} \mathrm{~N}_{2} \mathrm{O}_{2}$, structurally an analog of urea and initially synthesized in 1869 [1-4]. Although HU can exist in two tautomeric forms, the drug primarily adopts the keto form due to its significantly higher stability than the imino form. Moreover, $\mathrm{HU}$ is a weak acid containing three ionizable protons, with a pKa of 10.6 [5].

$\mathrm{HU}$ is a nonalkylating antineoplastic agent used for hematological malignancies, infectious diseases, and dermatology [6]. The first evidence of its antineoplastic effects was obtained in the late 1950s in experiments conducted on L1210 leukemia cells and solid tumors [7]. In the 1960s, clinical trials demonstrated the drug's efficacy mainly against myeloproliferative disorders $[2,3]$.
HU has an acceptable short-term toxicity profile in most patients and is currently used as the first-line of chemotherapy in hematological malignancies such as myeloproliferative neoplasm (MPN) characterized by a mutation in Janus kinase 2 (JAK2), calreticulin (CALR), and myeloproliferative leukemia virus oncogene (MPL) genes [8-11]. Also, this agent is indicated to treat sickle-cell anemia, HIV infection, and thrombocythemia $[2,3,12]$. Moreover, it is effective for the management of refractory psoriasis, likely due to inhibition of epithelial proliferation, thus restoring the typical appearance of the patient's thickened epidermis [13-15]. In addition, HU has been used as a palliative treatment for acute myelogenous leukemia in elderly patients unfit for intensive chemotherapy [16]. Because of its positive effects of therapy, this drug is defined as an "essential medicine" by the World Health Organization [17]. 


\section{Mechanisms of the Inhibition of Cell Proliferation by Hydroxyurea}

$\mathrm{HU}$ functions as a radiation sensitizer because of its capacity to synchronize cancer cells in the radiation-sensitive cell cycle phase and inhibit the repair response of DNA damage produced by radiation [18]. This drug abolishes the relatively radioresistant cells at the $S$ phase of the cell cycle, reducing highly DNA synthesizing cells and increasing the frequency of the surviving cells at the relatively radiosensitive portion (G1-S interphase) of the cell cycle (Figure 1) $[19,20]$. In addition, HU radio-sensitization in patients with advanced cervical cancer increases progression-free survival in the stages III and IVA disease cohort; moreover, HU activities have been evaluated in high-grade gliomas, nonsmall-cell lung cancer, head and neck cancer, and cervical carcinoma with different grades of success [21].

Furthermore, HU regulates tumor cell resistance to chemotherapy because it accelerates the loss of extrachromosomal amplified genes implicated in therapy sensitivity (Figure 1) [2, 22]. Moreover, it may induce metaphase chromosome fragmentation by directly affecting DNA integrity $[23,24]$. The drug cytotoxicity seems to be the result of the DNA damage caused by breaks during DNA synthesis inhibition, which explains its antineoplastic and teratogenic activity. Nonetheless, HU inhibition of DNA replication is reversible, indicating that the drug is likely a cytostatic agent [6]. Indeed, this agent inhibits DNA synthesis in several organisms and in vitro culture cells; thus, it is mainly active in the $S$ phase of the cell cycle, and the reversibility of its action serves as a cell cycle synchronizing agent in cell cultures [25-28].

Mechanistically, the ribonucleotide reductase (RNR), also known as ribonucleoside diphosphate reductase, is a well-established primary cellular target of HU (Figure 1). RNR is an iron-dependent tightly regulated enzyme that catalyzes the reduction of ribonucleoside diphosphates to deoxyribonucleotide (dNTP) precursors for de novo DNA replication and DNA repair [29-31]. Three main classes of RNRs have been described according to their metallocofactor requirements. In eukaryotes and eubacteria, class I RNRs are oxygen-dependent and contain a dinuclear metal cluster (Fe or Mn); the other classes II and III are found in aerobic and anaerobic microbes that require a cobalt-containing cobalamin (vitamin $\mathrm{B}_{12}$ ) cofactor and a $[4 \mathrm{Fe}-4 \mathrm{~S}]^{2+/ 1+}$ cluster coupled to $S$-adenosylmethionine (SAM) for catalytic activity, respectively [32]. Particularly, the mammalian RNR consists of two subunits, $\alpha$ and $\beta$, that can associate to form a heterodimeric tetramer, while the human genome encodes one $\alpha$ (RRM1) and two $\beta$ s (RRM2 and RRM2B) [33]. The $\alpha$ subunit contains binding domains for ribonucleotide substrates (NDPs/NTPs) and allosteric effectors, consequently regulating the RNR complex by nucleotide pools. In contrast, the $\beta$ subunit possesses catalytic activity and consists of a tyrosyl free radical stabilized by a nonheme iron center necessary for catalysis.

Moreover, the low cell capacity for RNR protein biosynthesis is the rate-limiting step in the de novo synthesis of DNA $[30,34]$. Since this enzyme catalyzes the rate-limiting step for DNA biosynthesis, its activity is fine-tuned to generate a periodic fluctuation of dNTP concentration during cell proliferation. In addition, maximum enzyme activity and RRM1 and RRM2 mRNA expression are observed in the S phase of the cell cycle where dNTPs are required $[35,36]$. Conversely, at the $G_{0} / G_{1}$ phase, the RNR activity is downregulated due to RRM2 gene transcriptional repression, and in the $\mathrm{M}$ cell cycle phase, the $\beta$ subunit is subjected to degradation pathways by the anaphase-promoting complex Cdh1 binding and consequent polyubiquitination [37, 38].

HU inhibits the RNR activity in vitro and in vivo, and the duration of DNA synthesis inhibition correlates with the level of deoxyribonucleotide pool reduction [39]. For RNR inhibition, HU, due to its small molecule size, penetrates the RRM2 subunit to directly reduce the diferric tyrosyl radical center via a one-electron transfer mechanism [40-44]. Interestingly, the electron transfer from $\mathrm{HU}$ to the tyrosyl radical may be mediated by the generation of nitric oxide-like radicals via $\mathrm{H}_{2} \mathrm{O}_{2}$-dependent peroxidation resulting from the reaction between this agent and the $\beta$ subunits $[44,45]$.

Because of the inhibition of RNR enzymatic activity by $\mathrm{HU}$, a reduction of the conversion of ribonucleotides to dNTP occurs, and the consequent dNTP depletion leads to an increase in DNA single-strand breaks [46, 47]. Moreover, the depletion of dNTP pools depends on the exposure length and drug concentration for the treatment $[48,49]$. The cell arrest in the S phase due to HU-induced dNTP pool reduction slows down DNA polymerase movement at replication forks, which, in eukaryotes, activates the S-phase checkpoint (also called the replication checkpoint kinase pathway). The S-phase checkpoint is a highly conserved intracellular signaling pathway crucial for the maintenance of genome stability under replication stress. In fact, the S-phase checkpoint preserves the functionality and structure of stalled DNA replication forks and prevents chromosome fragmentation [50-52]. When the S-phase checkpoint is activated, it stimulates RNR activity by increasing RNR $\beta$ subunit production and regulating its subcellular localization, while the RNR small inhibitor protein expression is downregulated. Furthermore, the activated S-phase checkpoint delays mitosis, suppresses the firing of late origin, and stabilizes the slowed replication forks against collapse, and this allows for the recovery of the regular DNA synthesis rate when the HU effect diminishes [51-54].

Because of low RNR activity, the deprivation of the dNTP pool below the threshold required to sustain DNA replication fork progression may provoke DNA replication fork collapse, which generates strand breaks and oxidative stress. In addition, HU can provoke direct DNA damage at thymine and cytosine residues in vitro, probably because of the $\mathrm{Cu}(\mathrm{II})$-mediated generation of nitric oxide and $\mathrm{H}_{2} \mathrm{O}_{2}$ [55]. Therefore, these HU's functions may directly cause the permanent effects observed in several cells and discussed later in the text $[56,57]$.

Even though $\mathrm{HU}$ inhibits the RNR activity, which is high in proliferating cells, cells can progress from $G_{1}$ to the $S$ phase at a relatively standard rate, where the drug promotes an accumulation of cells at the early S phase. Consequently, 


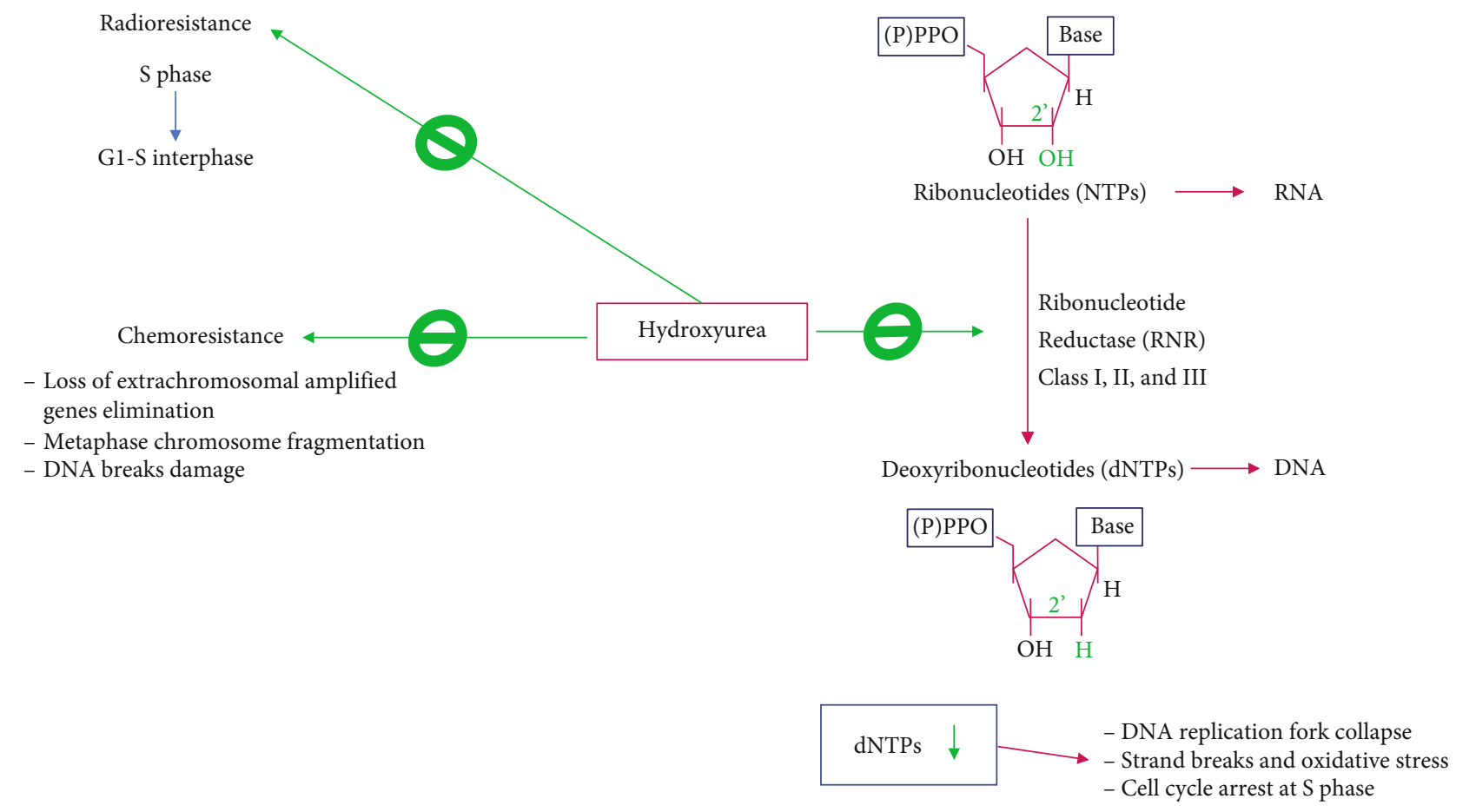

Figure 1: Main mechanisms of hydroxyurea cytotoxicity. HU functions as a radiation sensitizer by synchronizing cancer cells in the radiation-sensitive cell G1-S cycle interphase and inhibition of the DNA damage repair response. Also, HU sensitizes cancer cells to chemotherapy by promoting loss of extrachromosomal amplified gene elimination, metaphase chromosome, and DNA breaks damage. Moreover, HU inhibits the ribonucleotide reductase (RNR) that results in a drastic reduction of the deoxyribonucleotide pool necessary for DNA synthesis. Depletion of dNTPs promotes DNA replication fork collapse, strand break, and oxidative stress. For more details, see the text.

HU reduces the replication fork progression and DNA replication rate $[54,58]$. HU selectively eliminates cells in the $\mathrm{S}$ phase of highly proliferative cells that are most sensitive to the drug; as mentioned above, HU cytotoxic effects also depend on the dose and duration of exposure [39]. Besides specifically inhibiting RNR, HU also exerts other inhibitory functions on the replitase complex in the $\mathrm{S}$ phase of the cell cycle; replitase is a multienzyme complex of mammalian cells that produce dNTPs and deliver them to DNA synthesis by the DNA polymerase. Replitase complex comprises thymidine kinase, dihydrofolate reductase, nucleoside $-5^{\prime}$ -phosphate kinase, thymidylate synthase, and RNR itself $[59,60]$.

\section{Mechanism of Cellular Senescence}

Cellular senescence, defined as a process that causes an irreversible proliferative cell arrest with secretory features in response to several molecular and biological stressors, is a significant contributor to aging and age-related diseases [61-64]. This process was initially described by Hayflick and Moorhead in 1961 [65] when they observed that primary cells undergo a limited number of cell divisions in vitro. This observation allows suggesting a cellautonomous theory of aging that implies the depletion of active replicative cells required for tissue homeostasis and tissue repair and regenerative processes [62].
Cellular senescence encompasses different biological and molecular events that result in at least three senescence types (Figure 2): In replicative senescence (RS), the main mechanism relies on the number of cellular divisions in culture in vitro and, consequently, telomere shortening due to successive cell duplication [65-68]. Oncogene-induced senescence (OIS) is related to a tumor-suppressive mechanism as a response to oncogene overactivation and overexpression. Oncogenic activation seems to induce a stable growth arrest in premalignant cells from senescence expression, allowing a blockade of genetically unstable cells to progress to dangerous malignant stages. For instance, H-RAS mediates the induction of cell cycle inhibitor $\mathrm{p} 16^{\mathrm{INK} 4 \mathrm{~A}}$, which precludes the hyperphosphorylation of RB by the cyclin-Dand CDK4 and suppresses E2F activity. In addition, increased c-Myc expression promotes the $\mathrm{p} 14^{\mathrm{ARF}}$ transcription that stabilizes p53, thus accelerating cellular senescence [69-72]. The cellular senescence induced by oncological agents used at relevant therapeutic concentrations is called chemotherapy-induced senescence (CIS) [73].

In this last context, "immortal" cancer cells can undergo senescence from exposure to chemotherapeutic agents, causing severe cellular stress and displaying both protumorigenic and antitumorigenic functions [74, 75]. The chemotherapeutic armamentarium comprises genotoxic and cytotoxic drugs that target proliferating cells in a variety of cell cycle-dependent mechanisms (Figure 3) [76]. These drugs include topoisomerase inhibitors such as doxorubicin, 


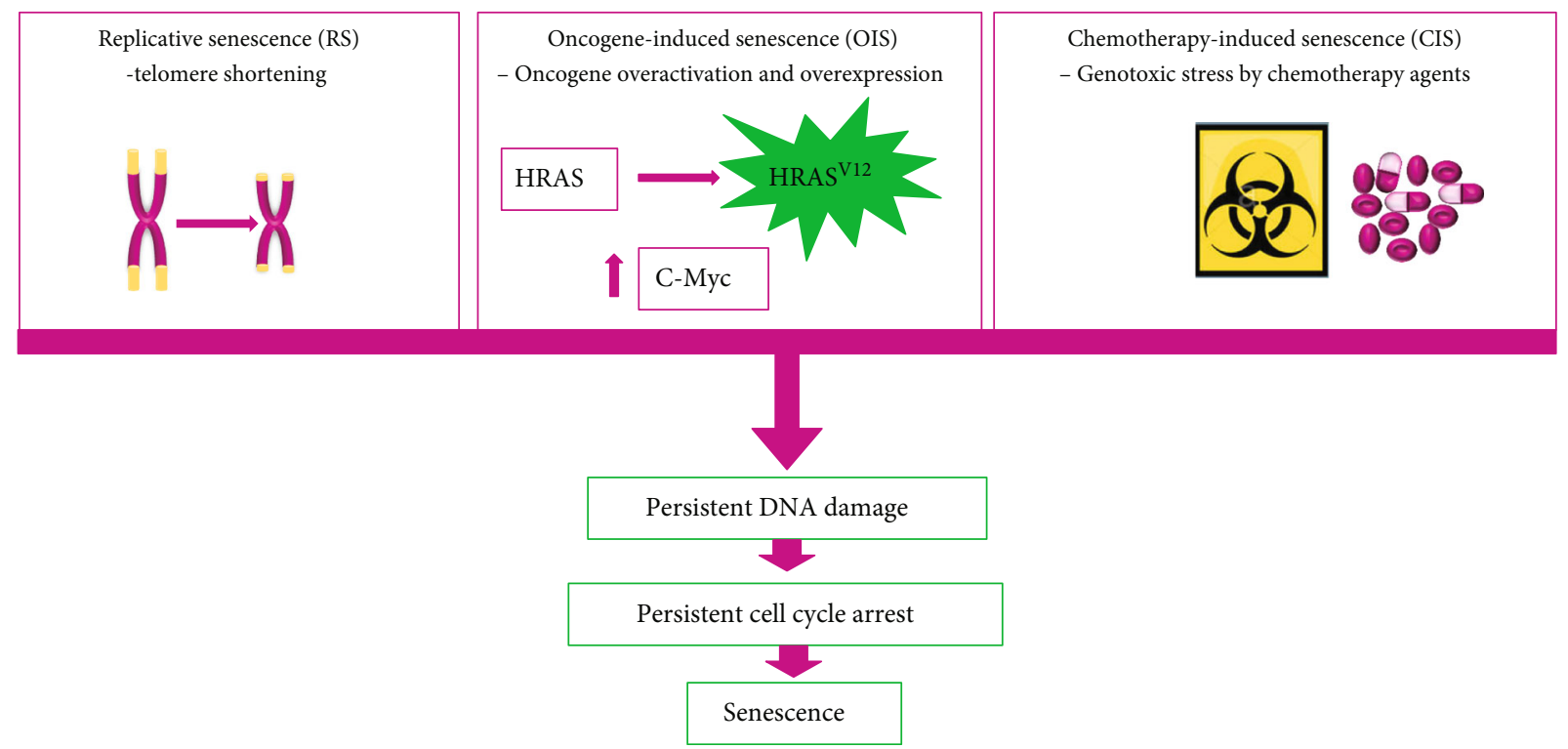

FIGURE 2: Mechanism of cellular senescence. The figure illustrates the main three senescence types that influence tumorigenesis: replicative senescence (RS) due to telomere shortening from a limited number of cell divisions, oncogene-induced senescence (OIS) due to an aberrant and sustained antiproliferative response to oncogenic signaling resulting from an oncogene-activating mutation and expression or the inactivation of a tumor-suppressor gene, and chemotherapy-induced senescence (CIS) due to cell response to severe genotoxic stress from exposure to a variety of onco-therapeutic agents.

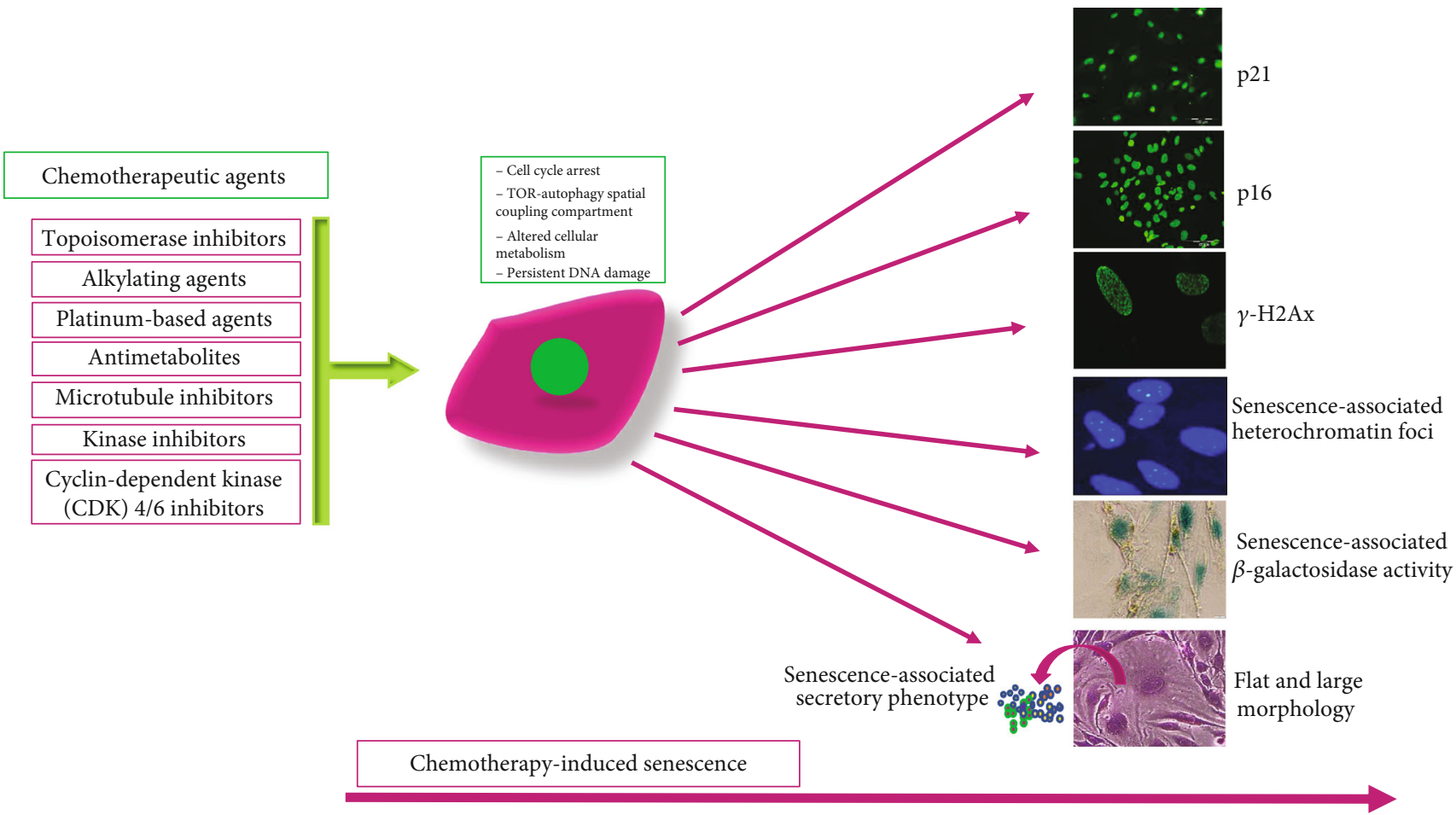

FIgURE 3: Chemotherapy-induced senescence. The figure indicates the main types of chemotherapeutic drugs with different mechanisms of action that induce genotoxic stress, triggering several cellular and molecular changes that result in the acquisition of senescence phenotype features indicated in the figure, such as increased $\mathrm{p} 21^{\mathrm{Cip} 1}, \mathrm{p} 16^{\mathrm{INK} 4}$, and $\gamma$-H2Ax expression, senescence-associated heterochromatin foci formation, expression and activity of senescence-associated $\beta$-galactosidase, senescence-associated secretory phenotype, and morphology changes in flat and enlarger cells. 
etoposide, and topotecan [77-80]; alkylating agents such as busulfan, cyclophosphamide, and mitomycin C [81-83]; platinum-based agents, including cisplatin, carboplatin, oxaliplatin [84-86]; antimetabolites such as methotrexate, gemcitabine, 5-fluorouracil, and hydroxyurea [87-90]; microtubule inhibitors that comprise paclitaxel, vincristine, and vinblastine [91-93]; kinase inhibitors such as vemurafenib, dasatinib, and lapatinib [94-96]; and cyclin-dependent kinase (CDK) 4/6 inhibitors, including palbociclib, abemaciclib, and ribociclib [97-99].

Interestingly, besides altering cellular cancer states, CIS also affects the tumor microenvironment by acting on noncancerous tissues and promoting immunosurveillance to eliminate tumor cells, while it also may contribute to chronic inflammation and cancer drug resistance [74, 100-102].

With senescence induction, cells display a stable cell cycle arrest and complex phenotypic and molecular changes, such as cell enlargement and flattening, altered cellular metabolism, and dysfunctional mitochondria, and the generation of the cytoplasmic target of rapamycin- (TOR-) autophagy spatial coupling compartment (TASCC) (Figure 3) [103, 104]. Moreover, senescent cells exhibit increased expression and activity of senescence-associated $\beta$-galactosidase (SA- $\beta$-gal), a lysosomal enzyme that in senescence conditions stains positive at $\mathrm{pH} 6$ and is one of the first characteristic molecular markers for senescence identification (Figure 3) [105]. Furthermore, because of the inherent molecular changes during the display of senescence features, cells suffer persistent damage such as DNA doublestrand breaks that triggers a persistent DNA damage response (DDR), resulting in permanent cell cycle arrest [106]. Specifically, DDR is a signaling cascade network that senses and repairs DNA lesions, thus preserving DNA integrity and preventing the generation of undesirable deleterious mutations, which under persistent or unrepairable DNA damage may drive cells toward apoptosis or cellular senescence [107]. In this sense, in higher organisms, the DDR prevents neoplastic transformation, ensuring the termination of cellular proliferation and the removal of severely damaged cells [108].

Cells may display senescence-associated heterochromatin foci (SAHF), detectable with immunostaining techniques (Figure 3), which result from the association of the retinoblastoma $(\mathrm{Rb})$ tumor suppressor and heterochromatin protein (HP) 1, DNA methyltransferase (DNMT) 1, or the suppressor of variegation 3-9 (Suv39) methyltransferase, which together form repressive complexes for the E2 transcription factor (E2F) 1 gene targets [109]. Moreover, the DNA damage caused by senescence inducers provokes the formation of persistent nuclear foci or DNA-SCARS characterized by chromatin alterations that reinforce cellular senescence [110]. In classical or normal reparative conditions, this process forms early foci that can be detected by $\gamma$-H2Ax or 53BP1 staining; in successful normal DNA repair, their expression rapidly disappears, while in senescence, these structures persist longer because of the elevated damage to the DNA, thus allowing the DNA-SCARS formation [111]. Moreover, DNA damage is sensed by ataxia telangiectasiamutated (ATM), an essential response kinase coordinating checkpoint, and senescence responses. ATM is activated by either DNA breaks or oxidative stress and plays an essential role in the senescence response by phosphorylating and stabilizing p53 [112-116]. From a molecular viewpoint (Figure 3), the upregulations of the tumor suppressor Rbp16 ${ }^{\text {INK4A }}$ and p53-P21 ${ }^{\text {Cip1 }}$ pathways (Figure 3) are molecular hallmarks that participate in the induction of cellular senescence by downregulating cyclin/CDK and inhibiting E2F1 activity $[62,117]$. In addition, downregulation of the nuclear lamina protein lamin B1 has also been postulated as a feature of the senescent phenotype $[118,119]$.

Even though cellular senescence implies a permanent cell cycle arrest, these cells remain metabolically active, earning the nickname "zombie" cells, and interact with other cells in the tumor microenvironment by cell-cell interaction or via the senescence-associated secretory phenotype (SASP), influencing the fate of neighboring cells via bystander effects (Figure 3) [120, 121]. The SASP encompasses a plethora of cytokines, growth factors, and proteases such as interleukin- (IL-) 1, IL-6, IL-8, growth-regulated oncogene (GRO) $\alpha / \beta$, granulocyte-macrophage colonystimulating factor (GM-CSF), insulin-like growth factor binding proteins (IGFBPs), matrix metalloproteinases(MMP-) 1, MMP-3, and MMP-10, intercellular adhesion molecule- (ICAM-) 1, and plasminogen activator inhibitor type 1 (PAI-1) [122, 123].

Nevertheless, a significant challenge is to typify senescence cells accurately. None of the above markers can be considered universal, and typifying senescence requires different phenotypical, biochemical, and molecular measurements. Recently, a combination of cytoplasmic markers, such as SA- $\beta$-gal, proliferation markers that are nuclearlocalized, including $\mathrm{p} 16^{\mathrm{INK} 4 \mathrm{AA}}, \mathrm{p} 21^{\mathrm{WAF} 1 / \mathrm{Cip} 1}, \mathrm{Ki} 67$, and SASP expression, have been recommended to standardize senescence characterization (Figure 3) [61].

Although CIS often is associated with tumor growth inhibition and regression [74], senescent cells may remain after the termination of onco-therapies and promote tumor progression by the SASP because they promote tumor cell dormancy, therapy resistance, and cancer relapse [64, 124-128]. In addition, SASPs influence the progression of surrounding nonsenescent tumor cells and metastasis by influencing the tumor microenvironment by factors that may promote the epithelial-to-mesenchymal transition (EMT), thus accelerating migration, invasion, and cancer cell malignancy features [129-132].

\section{Cellular Oxidative Stress and Hydroxyurea}

Reactive oxygen species (ROS) are constantly generated in normal physiological conditions, and they are eliminated by scavenging systems, thus maintaining cellular REDOX homeostasis. Meanwhile, dysbalance of this homeostasis due to aberrant ROS production or antioxidant decrease contributes to tumor progression and is a hallmark of several types of cancer (Table 1) [133, 134]. Moreover, exacerbated ROS levels result in biomacromolecular damage of proteins, lipids, and DNA among others, which promotes cellular 
TABLE 1: Reactive oxygen species and hydroxyurea main functions and effects on tumorigenesis.

\begin{tabular}{|c|c|c|}
\hline Function & Cellular and molecular effects & Ref. \\
\hline \multicolumn{3}{|l|}{ Reactive oxygen species } \\
\hline $\begin{array}{l}\text { Intracellular signaling pathway } \\
\text { regulation }\end{array}$ & Cell proliferation and survival, cell motility, invasiveness, and metastasis & [140] \\
\hline & $\begin{array}{l}\text { Telomere-dependent mechanism and telomere-independent mechanism } \\
\text { (i) Double-strand DNA breaks induction }\end{array}$ & \\
\hline Senescence induction & $\begin{array}{l}\text { (ii) DNA lesions due to } 8 \text {-oxo- } 2^{\prime} \text {-deoxyguanosine generation } \\
\text { (iii) Genomic instability } \\
\text { (iv) Gene mutations implicated in the following: } \\
\text { (a) Inhibition of tumor suppressor genes } \\
\text { (b) Activation of oncogenes }\end{array}$ & {$[143-147]$} \\
\hline $\begin{array}{l}\text { Regulation of cellular } \\
\text { proliferation }\end{array}$ & $\mathrm{H}_{2} \mathrm{O}_{2}$, superoxide $\left(\mathrm{O}_{2} \cdot{ }^{-}\right)$, and hydroxyl radical $(\mathrm{OH} \cdot)$ reduce cell proliferation & {$[148,149]$} \\
\hline \multicolumn{3}{|c|}{ Hydroxyurea and reactive oxygen species } \\
\hline Cytotoxicity & $\begin{array}{l}\text { Cytotoxicity and teratogenicity due to radical chain reactions, via } \mathrm{H}_{2} \mathrm{O}_{2} \text {, initiated by } \mathrm{HU} \\
\text { hydroxylamine group to form } \mathrm{R}-\mathrm{H} \dot{\mathrm{NO}} \mathrm{OH}^{+} \text {radical and generation of } \mathrm{NO}\end{array}$ & {$[150,151]$} \\
\hline $\begin{array}{l}\text { DNA damage by increasing } \\
\text { oxidative stress }\end{array}$ & Thymidine and cytosine damage via increasing $\mathrm{NO}$ and $\mathrm{H}_{2} \mathrm{O}_{2}$ and fork collapse & $\begin{array}{l}{[6,45,55,} \\
152]\end{array}$ \\
\hline Nitric oxide generation & RNR enzyme inhibition via $\mathrm{NO}$ and nitrosyl radical $\cdot \mathrm{NO}$ production & $\begin{array}{l}{[45,153,} \\
154]\end{array}$ \\
\hline Scavenger protein inhibition & Downregulation of superoxide dismutase-2, peroxiredoxin-1, and Sirtuins & {$[154-156]$} \\
\hline
\end{tabular}

senescence and aging and is associated with the physiopathology of several age-associated diseases [135].

ROS comprise a family of highly reactive molecules that regulate normal cellular conditions by fine control of the generation/consuming rate. In contrast, in cancer, a dysregulated oxidative stress is produced that contributes to the chemical damage of proteins, lipids, and DNA and tumorigenesis promotion [136]. From a molecular viewpoint, ROS are small molecules derived from the oxygen comprising free radical and nonfree radical oxygen intermediates, ions, or molecules that have a single unpaired electron in their outermost shell of electrons. Moreover, ROS are constantly generated inside cells by enzyme complexes or as by-products of REDOX reactions, including those underlying mitochondrial respiration $[137,138]$. These molecules include oxygen radicals, such as superoxide anion, hydroxyl, peroxyl, and alkoxyl, and nonradical molecules that are either oxidizing agents or easily converted into radicals, such as hypochlorous acid, ozone, singlet oxygen, and hydrogen peroxide. In addition, this oxygen-containing reactive species can combine with nitrogen to generate nitrogencontaining oxidants such as nitric oxide and peroxynitrite that belong to the family of reactive nitrogen species (RNS) $[136,138]$. Furthermore, the REDOX dysbalance in cancer cells is generated by increased cellular metabolic activity, mitochondrial dysfunction, deregulated cellular receptor signaling, peroxisome activity, oncogene activation, cyclooxygenase lipoxygenases, and thymidine phosphorylase. In addition, the contribution to the REDOX dysbalance of these factors may depend on the malignant stage of the cancer cells and their interaction with tumor stroma and infiltrating immune cells $[139,140]$. Furthermore, cellular superoxide anions form mainly because of the NADPH oxi- dase (NOX) family [141]. Five forms of NOXs have been found: the small GTPase Rac1-dependent NOX1, NOX2, and NOX3, and the small GTPase Rac1-independent NOX4 and NOX5 [142].

ROS participate in different aspects of tumor development and progression; they regulate intracellular signaling pathways involved in cell proliferation and survival while also influencing cell motility, invasiveness, and metastasis and regulating inflammatory responses within the tumor stroma and in angiogenesis [140]. Furthermore, ROS contribute to determining mammalian cells' senescent cellular fate $[143,144]$. These oxygen-containing reactive species can promote cellular senescence by telomere-dependent mechanisms and telomere-independent mechanisms involving unrepairable single or double-strand DNA breaks [145, 146]. Moreover, their excessive levels generate DNA lesions by forming 8oxo- $2^{\prime}$-deoxyguanosine, which accumulates in senescent human cell cultures and aging mice. Consequently, this DNA damage generates genomic instability, DNA mutations, and tumor development [147]. Therefore, ROS produce genomic alterations such as point mutations and deletions, which may inhibit tumor-suppressor genes while activating and inducing the expression of oncogenes to further contribute to the enhancement of cancer cell malignancy [143].

On the other hand, ROS also regulates cellular proliferation, which depends on their levels and duration of exposure. In this sense, most cytostatic/cytotoxic anticancer drugs inhibit cancer cell proliferation and cell survival by promoting ROS generation [148, 149]. For instance, both $\mathrm{H}_{2} \mathrm{O}_{2}$ and its dismutation product superoxide $\left(\mathrm{O}_{2}{ }^{-}\right)$reduce cancer cell proliferation, while $\mathrm{H}_{2} \mathrm{O}_{2}$ may also form, via Fenton reaction, the hydroxyl radical $(\mathrm{OH} \cdot)$ that highly inhibits cell proliferation [149]. 
Although HU can enhance cellular oxidative stress, the intimate molecular mechanism is not well understood. Some earlier studies have suggested that this drug may exert cytotoxic effects through radical chain reactions via $\mathrm{H}_{2} \mathrm{O}_{2}$ and initiated by its hydroxylamine group. Conversely, radical scavengers substantially reduce the cytotoxic and teratogenic HU activities [150, 151]. Moreover, HU causes DNA damage to thymidine and cytosine residues via increasing $\mathrm{H}_{2} \mathrm{O}_{2}$, in part by inducing ROS via provoking a fork collapse. Moreover, this agent induces mutagenic DNA lesions in V79 Chinese hamster cells, likely due to the generation of $\mathrm{H}_{2} \mathrm{O}_{2}$ $[6,45,57,152]$.

Moreover, nitric oxide radical $(\cdot \mathrm{NO})$, generated upon the 3-electron oxidation of the drug, may be responsible for many of its pharmacologic effects, including the RNR enzyme inhibition [153, 154]. Nevertheless, recent analyses indicated that $\mathrm{HU}$ might downregulate the expression of scavenger proteins, such as superoxide dismutase (SOD) 2 and peroxiredoxin-1 (PRDX1), and regulatory oxidative stress proteins, such as Sirtuin- (Sirt-) 3 (Table 1) [154-156]. Although the involved molecular mechanisms by which $\mathrm{HU}$ regulates the expression of these proteins have not been well elucidated so far, the induced deficiency of these oxidative stress regulatory proteins significantly contributes to the elevation of ROS by HU and the establishment of cellular senescence.

\section{Hydroxyurea and Cellular Senescence}

HU inhibits proliferation in several organisms and cell lines. At therapeutically relevant levels, HU mainly induces cell proliferation arrest in the $S$ cell cycle phase because of the decrease in dNTPs by RNR enzymatic activity inhibition [157, 158]; this causes a reduction of DNA polymerase movement at replication forks that generate a DNA replication stress $[6,102]$. In cancer therapy, this agent is frequently used as an antitumor agent because of its cytoreduction functions. Moreover, HU belongs to the family of antimetabolite drugs that can induce premature cellular senescence from interfering with the crucial synthesis pathways required for DNA duplication (Figure 4) [102, 128].

One of the first observations that HU may promote senescence-like phenotype in cancer cells was made in the human erythroleukemia K562 cell line. K562 cells underwent cell proliferation arrest and positivity to SA- $\beta$-gal activity after seven days of $\mathrm{HU}$ treatment. Moreover, the treatment increased the expression of the cyclin-dependent kinase inhibitors $\mathrm{p} 16^{\mathrm{INK} 4 \mathrm{~A}}$ and $\mathrm{p} 21^{\mathrm{Cip} 1}$ [159]. Interestingly, since K562 cells are p53-deficient [160], HU-induced senescence can occur independently of p53 activity in these cells. Additionally, this agent also induces cellular senescence in rat hepatoma McA-RH7777 cells; after treatment, cells exhibited enlarged size, increased SA- $\beta$-gal positive staining, and a substantial reduction in cell proliferation as cells were arrested in the $G_{0} / G_{1}$ cell cycle phase. In this case, a substantial reduction in the cellular frequency at the $G_{2} / M$ phase was observed. Cells undergoing $\mathrm{HU}$ treatment consistently expressed elevated levels of p21 ${ }^{\text {Cip } 1}$ associated with cell cycle arrest at the $\mathrm{G}_{1} / \mathrm{S}$ interphase [161]. Likewise, the drug pro- motes cellular senescence in neuroblastoma cell lines after a relatively long period of treatment, in part because of $\mathrm{HU}$ concentrations below $200 \mu \mathrm{M}$. After five weeks of treatment, more than $50 \%$ of the cells stained positive for SA- $\beta$-gal, and in this period, cells exhibited a reduction of telomere length that was $50 \%$ of the cells after ten weeks [162]. Although this pharmaceutical compound induces neuroblastoma cell senescence in vitro, it does not promote cell secretion of unfavorable SASPs, such as MMP-9, the monocytechemotactic protein- (MCP-) 3, the regulated-on activation normal $\mathrm{T}$ cell expressed and secreted (RANTES), and the vascular endothelial growth factor (VEGF). In contrast, it induces secretion of IL- 6 and platelet-derived growth factor(PDGF-) AA, involved in immuno-regulation and angiogenesis [80, 163-165].

Besides cancer cells, HU may affect nontransformed cells. For instance, in a model of foreskin fibroblast cells, treatment with the drug in the range of $400-800 \mu \mathrm{M}$ provoked a reduction of cell proliferation and morphological changes similar to the findings in replicative cellular senescence; moreover, these changes were not reversible by removing the drug treatment. HU treatment induces SA- $\beta$ gal activity and p53 and p2 ${ }^{\text {Cip } 1}$ expression along with Jun $\mathrm{N}$-terminal kinase (JNK) activation. Moreover, because of HU treatment, senescence fibroblasts are protected from UV light-induced apoptosis [166]. Similar results were reported in a human embryonic fibroblast cell line; the treatment with this medical agent induced SA- $\beta$-gal and $\mathrm{p} 21^{\mathrm{Cip} 1}$; moreover, the elevated $\mathrm{p} 21^{\mathrm{Cip} 1}$ expression seemed due to increased protein stability rather than de novo synthesis. In addition, increased $\mathrm{p} 21^{\mathrm{Cip} 1}$ was independent of increased p53; thus, suggesting that in these cells, p53 activity was not implicated [167], which is concordant with the theory that p53 mainly transcriptionally activates $\mathrm{p} 21^{\mathrm{Cip} 1}$ expression [168]. In addition, the HU-induced senescence in mouse fibroblasts, determined by SA- $\beta$-gal activity, is increased by transcription factor c-Jun depletion, while cJun overexpression inhibits the senescence induced by the treatment and drives cells to cell death.

Meanwhile, the transcription factor JunB enhances HUinduced senescence by upregulation of their direct target $\mathrm{p} 16^{\mathrm{INK} 4 \mathrm{~A}}$. These results suggest that the balance between the c-Jun and JunB transcription factors may determine the cellular response to the chemotherapeutic HU agent [169]. In addition, the chronic exposure of rat and human fibroblasts to low concentrations of the chemotherapeutic agent induced cellular senescence by a p53-dependent $\mathrm{p} 21^{\mathrm{Cip} 1}$ expression and increased SA- $\beta$-al activity, but independent of $\mathrm{p} 16^{\mathrm{INK} 4 \mathrm{~A}}$. Moreover, $\mathrm{HU}$ induces reversible $\gamma$ H2A.X foci, indicating that replicational stress induced by HU promotes DNA strand breaks [58].

HU treatment also can induce postnatal subventricle neural stem cells (NSCs) to undergo cellular senescence [154]. In this case, elevated concentrations of the drug (at $\mathrm{mM}$ levels) cause persistent DNA damage evidenced by $\gamma \mathrm{H} 2 \mathrm{AX}$ foci formation and a consistently increasing number of SA- $\beta$-gal positive cells, as well as increased $\mathrm{p} 16^{\mathrm{INK} 4 \mathrm{~A}}$, $\mathrm{p} 21^{\mathrm{Cip1}}$, and $\mathrm{p} 53$ expression. Moreover, under HU treatment, cells suffered a reduction of proliferation as a 


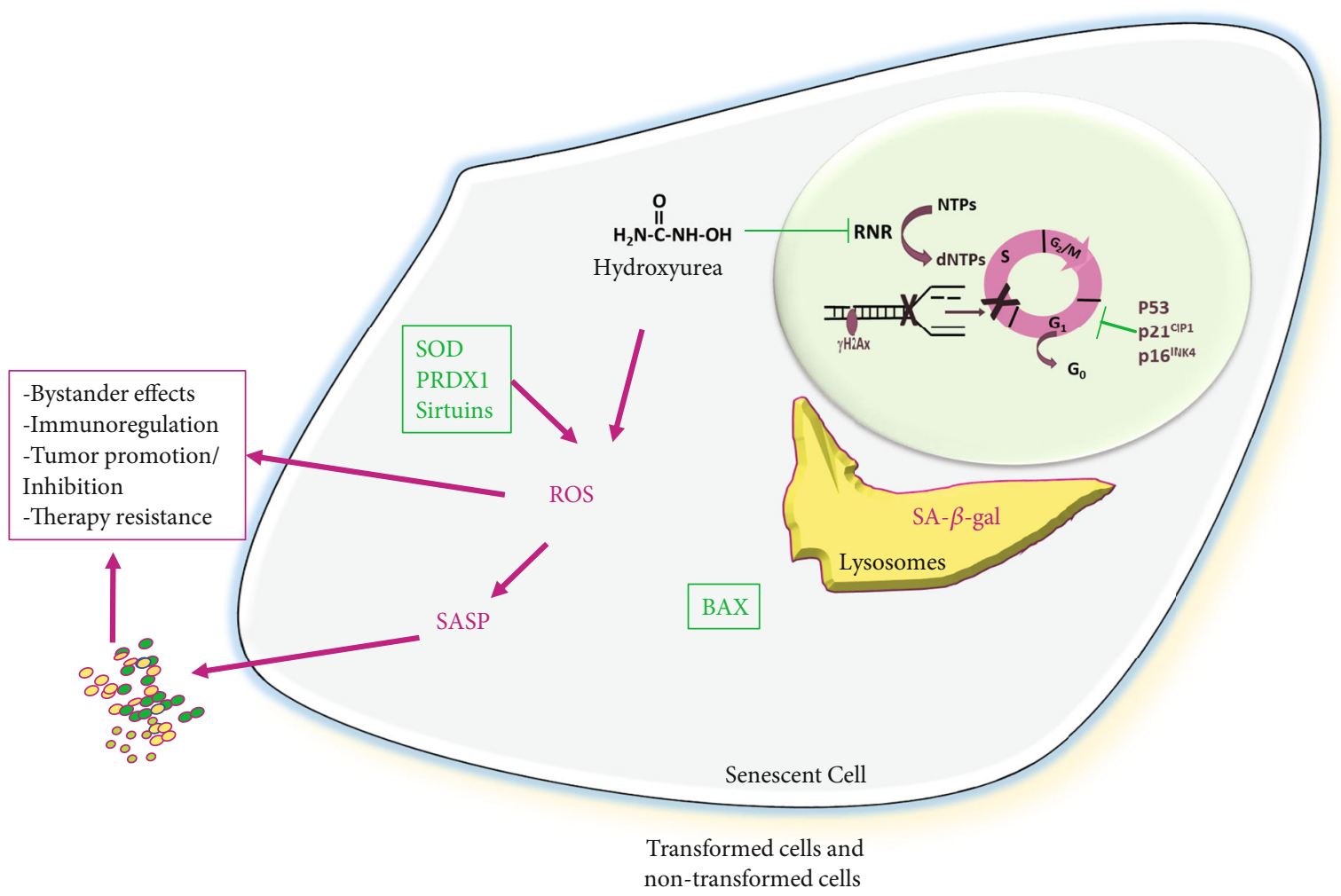

Figure 4: Overview of the main features of hydroxyurea-induced cellular senescence. Hydroxyurea, by inhibition of ribonucleotide reductase (RNR), dramatically reduces the synthesis of deoxyribonucleotides (dNTPs) from ribonucleotide substrates (NTPs). This dNTP pool reduction provokes a termination of DNA replication and may result in replication fork collapse. Furthermore, because of genotoxic $\mathrm{HU}$ action, DNA damage is generated, and phosphorylated histone $\mathrm{H} 2 \mathrm{AX}(\gamma \mathrm{H} 2 \mathrm{AX})$ binding to DNA breaks is promoted. Cells may suffer an arrest at the $\mathrm{S}$ cell cycle phase, concomitant with increased expression of cell cycle inhibitors p16 ${ }^{\mathrm{INK} 4 \mathrm{~A}}$, p2 $1^{\text {Cip } 1}$, and p53, reinforcing the cell cycle inhibition. During senescence induction, cell size is enlarged, and lysosomal biogenesis is increased, as indicated by elevated levels of expression and senescence-associated- $\beta$-galactosidase (SA- $\beta$-gal). Along with DNA replication inhibition, augmentation of oxidative stress occurs as reactive oxygen species (ROS) expression levels are elevated, consistently reducing antioxidative stress protein superoxide dismutase (SOD) 2, peroxiredoxin (PRDX) 1, and Sirtuins that contribute to maintaining increased oxidative stress. Moreover, HU-induced senescent cells are refractory to apoptosis, in part from reduced expression of the proapoptotic BAX protein. Senescent cells are metabolically active, and they express and release a set of factors as part of the senescenceassociated secretory phenotype (SASP). The SASP may profoundly influence surrounding cells and tissues through increased local and systemic inflammation and regulation of immune response, depending on SASP pattern, positively or negatively affecting tumor growth, and may also contribute to therapy resistance. Magenta words mean increased expression. Magenta arrows mean induction. Gree Tshape symbols mean inhibition. Green words mean reduced expression.

consequence of a cell cycle arrest at $\mathrm{G}_{0} / \mathrm{G}_{1}$. Furthermore, the treatment increased intracellular ROS levels along with a significant decrease in SOD2 and PRDX1. SOD2 is a main antioxidant enzyme that scavenges ROS in the inner mitochondrial matrix and acts as the first defense against mitochondrial oxidative stress [170], while PRDX1 is a thiol-specific peroxidase that scavenges hydrogen peroxide [171]. In addition, this pharmaceutical agent provokes a downregulation of Bcl-2-associated X protein (BAX), a critical proapoptotic factor that may contribute to the decreased apoptosis observed in senescent NSCs [154, 172]. In addition, HU-induced NSC cellular senescence is counteracted by $\alpha$-glycerylphosphorylethanolamine (GPE) [173], which is a precursor biomolecule of phospholipid synthesis and exerts neuroprotective effects in human hippocampal cells [174]. For instance, GPE protects NSCs from the induction of DNA damage caused by phosphorylated $\gamma \mathrm{H} 2 \mathrm{AX}$ levels and rescues cell proliferation from HU inhibition. Further- more, GPE highly reduces HU-induced SA- $\beta$-gal expression and activity and p53 and p $21^{\mathrm{Cip} 1} \mathrm{mRNA}$ expression. Moreover, this chemotherapeutic agent increases the ADP/ATP ratio that indicates mitochondrial energy metabolism impairment, while GPE restores the physiological ADP/ATP ratio and significantly reduces $\mathrm{HU}$-induced ROS levels. GPE also consistently inhibits the ROS-responsive NF- $\kappa$ B signaling [175]. Thus, GPE protects NSCs from HU-induced cellular senescence, indicating that it might function as an antiaging compound for NSCs [173].

$\mathrm{HU}$ can also induce cellular senescence of mesenchymal stem/stromal cells (MSCs). MSCs are multipotent cells characterized by their ability to differentiate into adipocytes, chondrocytes, and osteoblasts; their expression of surface markers CD73, CD90, and CD105; and their lack of hematopoietic lineage markers $[176,177]$. They are also present in the tumor microenvironment, where they support the growth of tumor cells, activate mitogen and stress signaling, 
and increase resistance to cytotoxins $[178,179]$. HU at relatively high levels inhibits dental follicle-derived MSC proliferation and clone formation capacity along with increased DNA double-strand breaks indicated by $\gamma \mathrm{H} 2 \mathrm{AX}$ foci formation; additionally, it induces SA- $\beta$-gal activity and a higher expression level of p53, p $21^{\mathrm{Cip} 1}$, and $\mathrm{p} 16^{\mathrm{INK} 4 \mathrm{~A}}$. These effects are accompanied by reducing MSC differentiation toward adipogenic, chondrogenic, and osteogenic lineages.

Moreover, senescence induction by $\mathrm{HU}$ increases ROS levels along with the downregulation of SOD2 [155]. Similarly, peripheral blood MSCs (PB-MSCs) are also targeted by this agent [180]. HU induces a senescence-like phenotype in PB-MSC as it provokes substantial cell morphology changes accompanied by SA- $\beta$-gal and $\mathrm{p} 16^{\mathrm{INK} 4 \mathrm{~A}}$ expression with a discrete effect on $\mathrm{p} 21^{\mathrm{Cip} 1}$ expression. The treatment with the drug at therapeutically relevant concentrations $(200 \mu \mathrm{M})$ strongly induces cell cycle arrest to the $\mathrm{S}$ cell cycle phase; consistent with that, in the presence of $\mathrm{HU}$, cells progress from $G_{1}$ to the $S$ phase at a normal rate and are arrested in the early $S$ phase [58]. This pharmaceutical compound also increases intracellular ROS levels that contribute to senescence induction because oxidative stress scavengers, $\mathrm{N}$-acetylcysteine, and NOX inhibitor apocynin inhibit cellular senescence and partially protect PB-MSC proliferation from inhibition by HU. Furthermore, HU-induced senescent PB-MSCs significantly inhibit the proliferation of erythroleukemia cells by secreting TGF- $\beta 1$ and elevated ROS production. Thus, senescent PB-MSCs may shift from a tumor-promoter activity to a tumor-suppressive function [180].

As stated, HU during senescence induction promotes an elevation of cellular ROS in part because of downregulation of SOD2, and recently, it was reported that this drug could also inhibit the expression of Sirt-3 (Figure 4) [156]. Sirt-3 is a mitochondrial deacetylase that regulates major mitochondrial biological processes, including ATP generation, ROS detoxification, nutrient oxidation, mitochondrial dynamics, and the unfolded protein response [181, 182]. Sirt-3 also deacetylates and thereby activates SOD-2 [183]. $\mathrm{HU}$ induces mouse embryonic fibroblast (MEF) senescence and increases ROS levels and Sirt-3 and SOD2 downregulation. Interestingly, adjudin is a compound derived from the anticancer drug lonidamine that acts through Sirt-3 activation [184]. Adjudin delays HU-induced cellular senescence reducing ROS levels by Sirt-3 upregulation [156]. Although it reduces the anti-ROS proteins Sirt-3 and SOD-2 expression during cell senescence induction, no molecular mechanism implicated in their downregulation has yet been elucidated. Nevertheless, it is important to reveal the underlying mechanistic pathways of elevated ROS levels due to HU treatment. Moreover, adjudin, due to its antisenescence function, may contribute to the therapy for age-associated diseases and CIS.

Similarly, 1,5-isoquinolinediol (IQD), a poly (ADPribose) polymerase (PARP1) inhibitor, protects MEF cells from HU-induced senescence [185]. PARPs perform poly(ADP-ribosyl)ation of proteins as an immediate cellular response to genotoxic insults induced by ionizing radiation, alkylating agents, and oxidative stress [186]. HU accelerates the MEF replicative senescence rate by inducing oxidative stress paralleled to increasing PARP1 and lamin A expression, while IQD effectively suppresses the senescence rate by decreasing the activity of PARP1 [185]. Noticeably, the increased expression and activity of PARP1 rapidly consume the NAD+ necessary for Sirt-1 function, so the decreased Sirt-1 activity results in increased oxidative stress. Thus, pharmacological PARP1 inhibition may restore NAD+ levels and Sirt-1 activity and normalize oxidative metabolism [187], which may help control the prosenescence function of $\mathrm{HU}$ and prevent chemotherapy-associated accelerated aging in cancer survivors [188].

\section{Concluding Remarks}

$\mathrm{HU}$ as a nonalkylating antiproliferative agent is still used to manage a variety of disease conditions in both neoplastic and nonneoplastic settings, and it is listed as an essential medicine by WHO. This drug can function as a cytoreductive agent because of its cytostatic properties; in this sense, as is analyzed in this review, HU can induce cellular senescence in both cancer cells and nontransformed cells, which profoundly affects tumor growth and homeostatic function of normal cells. Mechanistically, this compound functions as an antimetabolite agent by acting on RNR and affecting the generation of the dNTP pools necessary for DNA synthesis and duplication. The dNTP deficiency may cause fork collapse associated with DNA damage and ROS generation, which contributes to establishing a cellular senescence phenotype. What is the molecular mechanism by which HU increases ROS? It is a relevant question to address experimentally; cells under treatment may exhibit reduced expression of antioxidative stress, SOD2, PRDX1, and Sirtuins that contribute to the enhancement and stabilization of elevated ROS levels. For instance, repression of SOD2 may occur at the level of epigenetic regulation [189], and HU may promote epigenetic modifications along with regulation of several intracellular signal transductions, such as MAPK, PKG, and PKA signaling [190], which, in part, may explain the reduced expression of SOD2 during the increase in ROS levels and the cellular senescence due to HU treatment.

Different strategies have emerged to eliminate CIS cells because of the need to eliminate tumor cells and nontransformed dysfunctional cells. To this end, senolytic strategies have been developed to target CIS-transformed cells and, potentially, the nontransformed senescent cells without affecting normal proliferating cells [191]. In addition, the increased ROS levels that contribute to HUinduced cellular senescence are valuable targets for developing therapeutic strategies to improve the cytotoxic function of the drug, which may shift cells from the senescence response toward cell death fate [192]. Understanding the delicate balance between cellular senescence and the beneficial anticancer function of $\mathrm{HU}$ is vital to improving the current therapies to impact the life quality of patients and control the undesirable premature aging caused by chemotherapy. 


\section{Data Availability}

No datasets were generated or analyzed during the current study.

\section{Conflicts of Interest}

The authors declare no conflict of interest.

\section{Acknowledgments}

Although relevant to the issues dealt with in this review, we apologize to those colleagues whose work has not been included due to space limitations. This work was supported by the Ministry of Education, Science and Technological Development of the Republic of Serbia, grant No. 451-039/2021-14/200015. We also thank the support of the visiting professor program of UBO to JFS.

\section{References}

[1] W. F. Dresler and R. Stein, "Ueber den Hydroxylharnstoff," Annalen der Chemie und Pharmacie, vol. 150, no. 2, pp. 242-252, 1869.

[2] P. R. Gwilt and W. G. Tracewell, "Pharmacokinetics and pharmacodynamics of hydroxyurea," Clinical Pharmacokinetics, vol. 34, no. 5, pp. 347-358, 1998.

[3] P. Navarra and P. Preziosi, "Hydroxyurea: new insights on an old drug," Critical Reviews in Oncology/Hematology, vol. 29, no. 3, pp. 249-255, 1999.

[4] W. G. Tracewell, D. L. Trump, W. P. Vaughan, D. C. Smith, and P. R. Gwilt, "Population pharmacokinetics of hydroxyurea in cancer patients," Cancer Chemotherapy and Pharmacology, vol. 35, no. 5, pp. 417-422, 1995.

[5] S. B. King, "The nitric oxide producing reactions of hydroxyurea," Current Medicinal Chemistry, vol. 10, no. 6, pp. 437452, 2003.

[6] A. Singh and Y. J. Xu, "The cell killing mechanisms of hydroxyurea," Genes, vol. 7, no. 11, p. 99, 2016.

[7] B. Stearns, K. A. Losee, and J. Bernstein, "Hydroxyurea. A new type of potential antitumor Agent1," Journal of Medicinal Chemistry, vol. 6, no. 2, p. 201, 1963.

[8] M. M. Heeney, M. R. Whorton, T. A. Howard, C. A. Johnson, and R. E. Ware, "Chemical and functional analysis of hydroxyurea oral solutions," Journal of Pediatric Hematology/Oncology, vol. 26, no. 3, pp. 179-184, 2004.

[9] R. Latagliata, A. Spadea, M. Cedrone et al., "Symptomatic mucocutaneous toxicity of hydroxyurea in Philadelphia chromosome-negative myeloproliferative neoplasms: the Mister Hyde face of a safe drug," Cancer, vol. 118, no. 2, pp. 404-409, 2012.

[10] R. A. Mesa, "How I treat symptomatic splenomegaly in patients with myelofibrosis," Blood, vol. 113, no. 22, pp. 5394-5400, 2009.

[11] K. Sokol, D. Tremblay, S. Bhalla, R. Rampal, and J. O. Mascarenhas, "Implications of mutation profiling in myeloid malignancies-part 2: myeloproliferative neoplasms and other myeloid malignancies," Oncology, vol. 32, no. 5, pp. e45-e51, 2018.
[12] F. Lori and J. Lisziewicz, "Hydroxyurea: overview of clinical data and antiretroviral and immunomodulatory effects," Antiviral Therapy, vol. 4, Suppl 3, pp. 101-108, 1999.

[13] Leavell UW Jr and J. W. Yarbro, "Hydroxyurea. A new treatment for psoriasis," Archives of Dermatology, vol. 102, no. 2, pp. 144-150, 1970.

[14] M. Rosten, "Hydroxyurea: a new antimetabolite in the treatment of psoriasis," The British Journal of Dermatology, vol. 85, no. 2, pp. 177-181, 1971.

[15] G. Weinlich and P. Fritsch, "Leg ulcers in patients treated with hydroxyurea for myeloproliferative disorders: what is the trigger?," The British Journal of Dermatology, vol. 141, no. 1, pp. 171-172, 1999.

[16] A. K. Burnett, D. Milligan, A. G. Prentice et al., "A comparison of low-dose cytarabine and hydroxyurea with or without all-trans retinoic acid for acute myeloid leukemia and highrisk myelodysplastic syndrome in patients not considered fit for intensive treatment," Cancer, vol. 109, no. 6, pp. 11141124, 2007.

[17] "19th WHO Model List of Essential Medicines," April 2015, http://www.who.int/medicines/publications/ essentialmedicines/EML2015_8-May-15.pdf.

[18] Y. Maruyama, C. Magura, and J. Feola, "Radiation sensitivity change of hemopoietic cells induced by hydroxyurea," Acta Radiologica: Oncology, Radiation, Physics, Biology, vol. 18, no. 2, pp. 136-144, 1979.

[19] S. E. Vogl, F. Camacho, B. H. Kaplan, H. Lerner, and J. Cinberg, "Hydroxyurea fails to improve the results of MBD chemotherapy in cancer of the head and neck, but reduces toxicity," Cancer, vol. 52, no. 11, pp. 2011-2016, 1983.

[20] W. K. Sinclair, "The combined effect of hydroxyurea and Xrays on Chinese hamster cells in vitro," Cancer Research, vol. 28, no. 2, pp. 198-206, 1968.

[21] F. B. Stehman, B. N. Bundy, G. Thomas et al., "Hydroxyurea versus misonidazole with radiation in cervical carcinoma: long-term follow-up of a Gynecologic Oncology Group trial," Journal of Clinical Oncology, vol. 11, no. 8, pp. 1523-1528, 1993.

[22] R. D. Christen, D. R. Shalinsky, and S. B. Howell, "Enhancement of the loss of multiple drug resistance by hydroxyurea," Seminars in Oncology, vol. 19, 3 Supplement 9, pp. 94-100, 1992.

[23] E. Borenfreund, M. Krim, and A. Bendich, "Chromosomal aberrations induced by hyponitrite and hydroxylamine derivatives," Journal of the National Cancer Institute, vol. 32, pp. 667-679, 1964.

[24] D. Veale, B. M. Cantwell, N. Kerr, A. Upfold, and A. L. Harris, "Phase 1 study of high-dose hydroxyurea in lung cancer," Cancer Chemotherapy and Pharmacology, vol. 21, no. 1, pp. 53-56, 1988.

[25] J. Timson, "Hydroxyurea," Mutation Research, vol. 32, no. 2, pp. 115-131, 1975.

[26] W. K. Sinclair, "Hydroxyurea: differential lethal effects on cultured mammalian cells during the cell cycle," Science, vol. 150 , no. 3704 , pp. 1729-1731, 1965.

[27] W. K. Sinclair, "Hydroxyurea: effects on Chinese hamster cells grown in culture," Cancer Research, vol. 27, no. 2, pp. 297-308, 1967.

[28] S. C. Barranco and J. K. Novak, "Survival responses of dividing and nondividing mammalian cells after treatment with 
hydroxyurea, arabinosylcytosine, or adriamycin," Cancer Research, vol. 34, no. 7, pp. 1616-1618, 1974.

[29] M. Kolberg, K. R. Strand, P. Graff, and K. K. Andersson, "Structure, function, and mechanism of ribonucleotide reductases," Biochimica et Biophysica Acta (BBA)-Proteins and Proteomics, vol. 1699, no. 1-2, pp. 1-34, 2004.

[30] P. Nordlund and P. Reichard, "Ribonucleotide reductases," Annual Review of Biochemistry, vol. 75, no. 1, pp. 681-706, 2006.

[31] J. Stubbe, "Ribonucleotide reductases," Advances in Enzymology and Related Areas of Molecular Biology, vol. 63, pp. 349419, 2006.

[32] C. Zhang, G. Liu, and M. Huang, "Ribonucleotide reductase metallocofactor: assembly, maintenance and inhibition," Frontiers in Biology, vol. 9, no. 2, pp. 104-113, 2014.

[33] H. Tanaka, H. Arakawa, T. Yamaguchi et al., "A ribonucleotide reductase gene involved in a p53-dependent cell-cycle checkpoint for DNA damage," Nature, vol. 404, no. 6773, pp. 42-49, 2000.

[34] R. A. Finch, M. Liu, S. P. Grill et al., "Triapine (3-aminopyridine-2-carboxaldehyde- thiosemicarbazone): a potent inhibitor of ribonucleotide reductase activity with broad spectrum antitumor activity," Biochemical Pharmacology, vol. 59, no. 8, pp. 983-991, 2000.

[35] Y. Engström, S. Eriksson, I. Jildevik, S. Skog, L. Thelander, and B. Tribukait, "Cell cycle-dependent expression of mammalian ribonucleotide reductase. Differential regulation of the two subunits.," The Journal of Biological Chemistry, vol. 260, no. 16, pp. 9114-9116, 1985.

[36] S. Eriksson, A. Gräslund, S. Skog, L. Thelander, and B. Tribukait, "Cell cycle-dependent regulation of mammalian ribonucleotide reductase. The $\mathrm{S}$ phase-correlated increase in subunit M2 is regulated by de novo protein synthesis.," The Journal of Biological Chemistry, vol. 259, no. 19, pp. 1169511700, 1984.

[37] A. L. Chabes, C. M. Pfleger, M. W. Kirschner, and L. Thelander, "Mouse ribonucleotide reductase R2 protein: a new target for anaphase-promoting complex-Cdh1mediated proteolysis," Proceedings of the National Academy of Sciences of the United States of America, vol. 100, no. 7, pp. 3925-3929, 2003.

[38] A. L. Chabes, S. Björklund, and L. Thelander, "S Phasespecific Transcription of the Mouse Ribonucleotide Reductase R2 Gene Requires Both a Proximal Repressive E2Fbinding Site and an Upstream Promoter Activating Region," The Journal of Biological Chemistry, vol. 279, no. 11, pp. 10796-10807, 2004.

[39] J. W. Yarbro, "Mechanism of action of hydroxyurea," Seminars in Oncology, vol. 19, 3 Suppl 9, pp. 1-10, 1992.

[40] I. Kjoller Larsen, B. M. Sjooberg, and L. Thelander, "Characterization of the active site of ribonucleotide reductase of Escherichia coli, bacteriophage T4 and mammalian cells by inhibition studies with hydroxyurea analogues," European Journal of Biochemistry, vol. 125, no. 1, pp. 75-81, 1982.

[41] J. L. Sneeden and L. A. Loeb, "Mutations in the R2 Subunit of Ribonucleotide Reductase That Confer Resistance to Hydroxyurea," The Journal of Biological Chemistry, vol. 279, no. 39, pp. 40723-40728, 2004.

[42] I. H. Krakoff, N. C. Brown, and P. Reichard, "Inhibition of ribonucleoside diphosphate reductase by hydroxyurea," Cancer Research, vol. 28, no. 8, pp. 1559-1565, 1968.
[43] S. Nyholm, L. Thelander, and A. Graeslund, "Reduction and loss of the iron center in the reaction of the small subunit of mouse ribonucleotide reductase with hydroxyurea," Biochemistry, vol. 32, no. 43, pp. 11569-11574, 1993.

[44] G. Lassmann, L. Thelander, and A. Gräslund, "EPR stoppedflow studies of the reaction of the tyrosyl radical of protein R2 from ribonucleotide reductase with hydroxyurea," Biochemical and Biophysical Research Communications, vol. 188, no. 2, pp. 879-887, 1992.

[45] K. Sato, T. Akaike, T. Sawa et al., "Nitric oxide generation from hydroxyurea via copper-catalyzed peroxidation and implications for pharmacological actions of hydroxyurea," Japanese Journal of Cancer Research, vol. 88, no. 12, pp. 1199-1204, 1997.

[46] E. Frenkel, W. Skinner, and J. Smiley, "Studies on a metabolic defect induced by hydroxyurea (NSC-32065)," Cancer Chemotherapy Reports, vol. 40, pp. 19-22, 1964.

[47] K. Madaan, D. Kaushik, and T. Verma, "Hydroxyurea: a key player in cancer chemotherapy," Expert Review of Anticancer Therapy, vol. 12, no. 1, pp. 19-29, 2012.

[48] S. S. Ford and S. E. Shackney, "Lethal and sublethal effects of hydroxyurea in relation to drug concentration and duration of drug exposure in sarcoma 180 in vitro," Cancer Research, vol. 37, 8 Part 1, pp. 2628-2637, 1977.

[49] R. E. Moran and M. J. Straus, "Cytokinetic analysis of L1210 leukemia after continuous infusion of hydroxyurea in vivo," Cancer Research, vol. 39, no. 5, pp. 1616-1622, 1979.

[50] A. Ciccia and S. J. Elledge, "The DNA damage response: making it safe to play with knives," Molecular Cell, vol. 40, no. 2, pp. 179-204, 2010.

[51] G. M. Alvino, D. Collingwood, J. M. Murphy, J. Delrow, B. J. Brewer, and M. K. Raghuraman, "Replication in hydroxyurea: it's a matter of time," Molecular and Cellular Biology, vol. 27, no. 18, pp. 6396-6406, 2007.

[52] M. Giannattasio and D. Branzei, "S-phase checkpoint regulations that preserve replication and chromosome integrity upon dNTP depletion," Cellular and Molecular Life Sciences, vol. 74, no. 13, pp. 2361-2380, 2017.

[53] J. Lopez-Mosqueda, N. L. Maas, Z. O. Jonsson, L. G. DefazioEli, J. Wohlschlegel, and D. P. Toczyski, "Damage-induced phosphorylation of Sld3 is important to block late origin firing," Nature, vol. 467, no. 7314, pp. 479-483, 2010.

[54] B. Grallert and E. Boye, "The multiple facets of the intra-S checkpoint," Cell Cycle, vol. 7, no. 15, pp. 2315-2320, 2008.

[55] K. Sakano, S. Oikawa, K. Hasegawa, and S. Kawanishi, "Hydroxyurea induces site-specific DNA damage via formation of hydrogen peroxide and nitric oxide," Japanese Journal of Cancer Research, vol. 92, no. 11, pp. 1166-1174, 2001.

[56] M. A. Marchetti, M. Weinberger, Y. Murakami, W. C. Burhans, and J. A. Huberman, "Production of reactive oxygen species in response to replication stress and inappropriate mitosis in fission yeast," Journal of Cell Science, vol. 119, no. 1, pp. 124-131, 2006.

[57] A. M. Carr and S. Lambert, "Replication stress-induced genome instability: the dark side of replication maintenance by homologous recombination," Journal of Molecular Biology, vol. 425, no. 23, pp. 4733-4744, 2013.

[58] A. Marusyk, L. J. Wheeler, C. K. Mathews, and J. DeGregori, "p 53 mediates senescence-like arrest induced by chronic replicational stress," Molecular and Cellular Biology, vol. 27, no. 15, pp. 5336-5351, 2007. 
[59] S. Murthy and G. P. Reddy, "Replitase: complete machinery for DNA synthesis," Journal of Cellular Physiology, vol. 209, no. 3, pp. 711-717, 2006.

[60] G. P. Reddy and R. S. Fager, "Replitase: a complex integrating dNTP synthesis and DNA replication," Critical Reviews in Eukaryotic Gene Expression, vol. 3, no. 4, pp. 255-277, 1993.

[61] V. Gorgoulis, P. D. Adams, A. Alimonti et al., "Cellular senescence: defining a path forward," Cell, vol. 179, no. 4, pp. 813827, 2019.

[62] B. G. Childs, M. Durik, D. J. Baker, and J. M. van Deursen, "Cellular senescence in aging and age-related disease: from mechanisms to therapy," Nature Medicine, vol. 21, no. 12, pp. 1424-1435, 2015.

[63] P. A. Pérez-Mancera, A. R. Young, and M. Narita, "Inside and out: the activities of senescence in cancer," Nature Reviews. Cancer, vol. 14, no. 8, pp. 547-558, 2014.

[64] S. Lee and C. A. Schmitt, "The dynamic nature of senescence in cancer," Nature Cell Biology, vol. 21, no. 1, pp. 94-101, 2019.

[65] C. B. Harley, A. B. Futcher, and C. W. Greider, "Telomeres shorten during ageing of human fibroblasts," Nature, vol. 345 , no. 6274 , pp. 458-460, 1990.

[66] R. C. Allsopp, E. Chang, M. Kashefi-Aazam et al., "Telomere Shortening Is Associated with Cell Division in Vitro and in Vivo," Experimental Cell Research, vol. 220, no. 1, pp. 194200, 1995.

[67] Fagagna F 'A, P. M. Reaper, L. Clay-Farrace et al., “A DNA damage checkpoint response in telomere-initiated senescence," Nature, vol. 426, no. 6963, pp. 194-198, 2003.

[68] F. d'Adda di Fagagna, S. H. Teo, and S. P. Jackson, "Functional links between telomeres and proteins of the DNAdamage response," Genes \& Development, vol. 18, no. 15, pp. 1781-1799, 2004.

[69] M. Serrano, A. W. Lin, M. E. McCurrach, D. Beach, and S. W. Lowe, "Oncogenic ras Provokes Premature Cell Senescence Associated with Accumulation of p53 and p16 ${ }^{\mathrm{INK} 4 \mathrm{a}}$," Cell, vol. 88, no. 5, pp. 593-602, 1997.

[70] J. Campisi, "Cellular senescence as a tumor-suppressor mechanism," Trends in Cell Biology, vol. 11, no. 11, pp. S27-S31, 2001.

[71] P. Hinds and J. Pietruska, "Senescence and tumor suppression," F1000Research, vol. 6, pp. 2121-2128, 2017.

[72] M. Collado, J. Gil, A. Efeyan et al., "Senescence in premalignant tumours," Nature, vol. 436, no. 7051, p. 642, 2005.

[73] I. B. Roninson, "Tumor cell senescence in cancer treatment," Cancer Research, vol. 63, no. 11, pp. 2705-2715, 2003.

[74] J. A. Ewald, J. A. Desotelle, G. Wilding, and D. F. Jarrard, "Therapy-induced senescence in cancer," Journal of the National Cancer Institute, vol. 102, no. 20, pp. 1536-1546, 2010.

[75] E. Fitsiou, A. Soto-Gamez, and M. Demaria, "Biological functions of therapy-induced senescence in cancer," Seminars in cancer biology, vol. S1044-579X, no. 21, pp. 00071-00077, 2021.

[76] G. K. Dy and A. A. Adjei, "Systemic cancer therapy: evolution over the last 60 years," Cancer, vol. 113, 7 Suppl, pp. 18571887, 2008.

[77] L. W. Elmore, C. W. Rehder, X. di et al., "Adriamycininduced Senescence in Breast Tumor Cells Involves Functional p53 and Telomere Dysfunction," The Journal of Biological Chemistry, vol. 277, no. 38, pp. 35509-35515, 2002.
[78] S. R. Schwarze, V. X. Fu, J. A. Desotelle, M. L. Kenowski, and D. F. Jarrard, "The identification of senescence-specific genes during the induction of senescence in prostate cancer cells," Neoplasia, vol. 7, no. 9, pp. 816-823, 2005.

[79] T. Nagano, M. Nakano, A. Nakashima et al., "Identification of cellular senescence-specific genes by comparative transcriptomics," Scientific Reports, vol. 6, no. 1, article 31758, 2016.

[80] S. Taschner-Mandl, M. Schwarz, J. Blaha et al., "Metronomic topotecan impedes tumor growth of MYCN-amplified neuroblastoma cells in vitro and in vivo by therapy induced senescence," Oncotarget, vol. 7, no. 3, pp. 3571-3586, 2016.

[81] C. A. Schmitt, J. S. Fridman, M. Yang et al., "A Senescence Program Controlled by $\mathrm{p} 53$ and $\mathrm{p} 16^{\mathrm{INK} 4 \mathrm{a}}$ Contributes to the Outcome of Cancer Therapy," Cell, vol. 109, no. 3, pp. 335346, 2002.

[82] Q. Mei, F. Li, H. Quan, Y. Liu, and H. Xu, "Busulfan inhibits growth of human osteosarcoma through miR-200 family microRNAsin vitroandin vivo," Cancer Science, vol. 105, no. 7, pp. 755-762, 2014.

[83] E. McKenna, F. Traganos, H. Zhao, and Z. Darzynkiewicz, "Persistent DNA damage caused by low levels of mitomycin C induces irreversible cell senescence," Cell Cycle, vol. 11, no. 16, pp. 3132-3140, 2012.

[84] X. Sun, B. Shi, H. Zheng et al., "Senescence-associated secretory factors induced by cisplatin in melanoma cells promote non-senescent melanoma cell growth through activation of the ERK1/2-RSK1 pathway," Cell Death \& Disease, vol. 9, no. 3, p. 260, 2018.

[85] R. S. Roberson, S. J. Kussick, E. Vallieres, S. Y. Chen, and D. Y. $\mathrm{Wu}$, "Escape from therapy-induced accelerated cellular senescence in p53-Null lung cancer cells and in human lung cancers," Cancer Research, vol. 65, no. 7, pp. 2795-2803, 2005.

[86] K. Qu, X. Xu, C. Liu et al., "Negative regulation of transcription factor FoxM1 by p53 enhances oxaliplatin- induced senescence in hepatocellular carcinoma," Cancer Letters, vol. 331, no. 1, pp. 105-114, 2013.

[87] D. K. Hattangadi, G. A. DeMasters, T. D. Walker et al., "Influence of p53 and caspase 3 activity on cell death and senescence in response to methotrexate in the breast tumor cell," Biochemical Pharmacology, vol. 68, no. 9, pp. 1699-1708, 2004.

[88] D. E. Modrak, E. Leon, D. M. Goldenberg, and D. V. Gold, "Ceramide regulates gemcitabine-induced senescence and apoptosis in human pancreatic cancer cell lines," Molecular Cancer Research, vol. 7, no. 6, pp. 890-896, 2009.

[89] X. Bu, C. Le, F. Jia et al., "Synergistic effect of mTOR inhibitor rapamycin and fluorouracil in inducing apoptosis and cell senescence in hepatocarcinoma cells," Cancer Biology \& Therapy, vol. 7, no. 3, pp. 392-396, 2008.

[90] R. Narath, I. M. Ambros, A. Kowalska, E. Bozsaky, P. Boukamp, and P. F. Ambros, "Induction of senescence in MYCN amplified neuroblastoma cell lines by hydroxyurea," Genes, Chromosomes \& Cancer, vol. 46, no. 2, pp. 130-142, 2007.

[91] A. Bojko, J. Czarnecka-Herok, A. Charzynska, M. Dabrowski, and E. Sikora, "Diversity of the senescence phenotype of cancer cells treated with chemotherapeutic agents," Cell, vol. 8, no. 12, p. 1501, 2019.

[92] L. Groth-Pedersen, M. S. Ostenfeld, M. Høyer-Hansen, J. Nylandsted, and M. Jäättelä, "Vincristine induces dramatic 
lysosomal changes and sensitizes cancer cells to lysosomedestabilizing siramesine," Cancer Research, vol. 67, no. 5, pp. 2217-2225, 2007.

[93] F. C. Kipper, A. O. Silva, A. L. Marc et al., "Vinblastine and antihelmintic mebendazole potentiate temozolomide in resistant gliomas," Investigational New Drugs, vol. 36, no. 2, pp. 323-331, 2018.

[94] S. Haferkamp, A. Borst, C. Adam et al., "Vemurafenib induces senescence features in melanoma cells," Journal of Investigative Dermatology, vol. 133, no. 6, pp. 1601-1609, 2013.

[95] S. Peng, B. Sen, T. Mazumdar et al., "Dasatinib induces DNA damage and activates DNA repair pathways leading to senescence in non-small cell lung cancer cell lines with kinaseinactivating BRAF mutations," Oncotarget, vol. 7, no. 1, pp. 565-579, 2016.

[96] M. S. J. McDermott, N. Conlon, B. C. Browne et al., "HER2targeted tyrosine kinase inhibitors cause therapy-inducedsenescence in breast cancer cells," Cancers, vol. 11, no. 2, p. 197, 2019.

[97] K. Michaud, D. A. Solomon, E. Oermann et al., "Pharmacologic inhibition of cyclin-dependent kinases 4 and 6 arrests the growth of glioblastoma multiforme intracranial xenografts," Cancer Research, vol. 70, no. 8, pp. 32283238, 2010.

[98] R. Torres-Guzmán, B. Calsina, A. Hermoso et al., "Preclinical characterization of abemaciclib in hormone receptor positive breast cancer," Oncotarget, vol. 8, no. 41, pp. 69493-69507, 2017.

[99] M. Iyengar, P. O'Hayer, A. Cole et al., "CDK4/6 inhibition as maintenance and combination therapy for high grade serous ovarian cancer," Oncotarget, vol. 9, no. 21, pp. 15658-15672, 2018.

[100] C. A. Schmitt, "Senescence, apoptosis and therapy - cutting the lifelines of cancer," Nature Reviews. Cancer, vol. 3, no. 4, pp. 286-295, 2003.

[101] Y. Sun, J. Campisi, C. Higano et al., "Treatment-induced damage to the tumor microenvironment promotes prostate cancer therapy resistance through WNT16B," Nature Medicine, vol. 18, no. 9, pp. 1359-1368, 2012.

[102] N. V. Petrova, A. K. Velichko, S. V. Razin, and O. L. Kantidze, "Small molecule compounds that induce cellular senescence," Aging Cell, vol. 15, no. 6, pp. 999-1017, 2016.

[103] M. Narita, A. R. Young, S. Arakawa et al., "Spatial coupling of mTOR and autophagy augments secretory phenotypes," Science, vol. 332, no. 6032, pp. 966-970, 2011.

[104] A. Hernandez-Segura, J. Nehme, and M. Demaria, "Hallmarks of cellular senescence," Trends in Cell Biology, vol. 28, no. 6, pp. 436-453, 2018.

[105] G. P. Dimri, X. Lee, G. Basile et al., "A biomarker that identifies senescent human cells in culture and in aging skin in vivo," Proceedings of the National Academy of Sciences of the United States of America, vol. 92, no. 20, pp. 9363-9367, 1995.

[106] F. Rossiello, U. Herbig, M. P. Longhese, M. Fumagalli, and F. d'Adda di Fagagna, "Irreparable telomeric DNA damage and persistent DDR signalling as a shared causative mechanism of cellular senescence and ageing," Current Opinion in Genetics \& Development, vol. 26, pp. 89-95, 2014.

[107] N. Malaquin, A. Carrier-Leclerc, M. Dessureault, and F. Rodier, "DDR-mediated crosstalk between DNA- damaged cells and their microenvironment," Frontiers in Genetics, vol. 6, p. 94, 2015.

[108] F. Rodier and J. Campisi, "Four faces of cellular senescence," The Journal of Cell Biology, vol. 192, no. 4, pp. 547-556, 2011.

[109] R. Zhang, W. Chen, and P. D. Adams, "Molecular dissection of formation of senescence-associated heterochromatin foci," Molecular and Cellular Biology, vol. 27, no. 6, pp. 2343-2358, 2007.

[110] C. Aging, "Cellular senescence, and cancer," Annual Review of Physiology, vol. 75, pp. 685-705, 2013.

[111] F. Rodier, D. P. Muñoz, R. Teachenor et al., "DNA-SCARS: distinct nuclear structures that sustain damage-induced senescence growth arrest and inflammatory cytokine secretion," Journal of Cell Science, vol. 124, no. 1, pp. 68-81, 2011.

[112] J. H. Lee and T. T. Paull, "ATM activation by DNA doublestrand breaks through the Mre11-Rad50-Nbs1 complex," Science, vol. 308, no. 5721, pp. 551-554, 2005.

[113] Z. Guo, S. Kozlov, M. F. Lavin, M. D. Person, and T. T. Paull, "ATM activation by oxidative stress," Science, vol. 330, no. 6003 , pp. 517-521, 2010.

[114] F. A. Mallette and G. Ferbeyre, "The DNA damage signaling pathway connects oncogenic stress to cellular senescence," Cell Cycle, vol. 6, no. 15, pp. 1831-1836, 2007.

[115] C. E. Canman, D. S. Lim, K. A. Cimprich et al., "Activation of the ATM kinase by ionizing radiation and phosphorylation of p 53," Science, vol. 281, no. 5383, pp. 1677-1679, 1998.

[116] M. Suzuki, K. Suzuki, S. Kodama, S. Yamashita, and M. Watanabe, "Persistent amplification of DNA damage signal involved in replicative senescence of normal human diploid fibroblasts," Oxidative Medicine and Cellular Longevity, vol. 2012, Article ID 310534, 8 pages, 2012.

[117] H. Rayess, M. B. Wang, and E. S. Srivatsan, "Cellular senescence and tumor suppressor gene p 16," International Journal of Cancer, vol. 130, no. 8, pp. 1715-1725, 2012.

[118] A. Freund, R. M. Laberge, M. Demaria, and J. Campisi, "Lamin B1 loss is a senescence-associated biomarker," Molecular Biology of the Cell, vol. 23, no. 11, pp. 2066-2075, 2012.

[119] E. Sikora, G. Mosieniak, and M. Alicja Sliwinska, "Morphological and functional characteristic of senescent cancer cells," Current Drug Targets, vol. 17, no. 4, pp. 377-387, 2016.

[120] T. Tchkonia, Y. Zhu, J. van Deursen, J. Campisi, and J. L. Kirkland, "Cellular senescence and the senescent secretory phenotype: therapeutic opportunities," The Journal of Clinical Investigation, vol. 123, no. 3, pp. 966-972, 2013.

[121] S. Lopes-Paciencia, E. Saint-Germain, M. C. Rowell, A. F. Ruiz, P. Kalegari, and G. Ferbeyre, "The senescenceassociated secretory phenotype and its regulation," Cytokine, vol. 117, pp. 15-22, 2019.

[122] J. P. Coppé, P. Y. Desprez, A. Krtolica, and J. Campisi, “The senescence-associated secretory phenotype: the dark side of tumor suppression," Annual Review of Pathology, vol. 5, no. 1, pp. 99-118, 2010.

[123] L. Cuollo, F. Antonangeli, A. Santoni, and A. Soriani, "The Senescence-Associated Secretory Phenotype (SASP) in the challenging future of cancer therapy and age-related diseases," Biology, vol. 9, no. 12, p. 485, 2020.

[124] S. Dodig, I. Čepelak, and I. Pavić, "Hallmarks of senescence and aging," Biochemia Medica, vol. 29, no. 3, article 030501, 2019.

[125] M. P. Baar, R. M. C. Brandt, D. A. Putavet et al., “Targeted apoptosis of senescent cells restores tissue homeostasis in 
response to chemotoxicity and aging," Cell, vol. 169, no. 1, pp. 132-147.e16, 2017.

[126] M. Demaria, M. N. O'Leary, J. Chang et al., "Cellular senescence promotes adverse effects of chemotherapy and cancer relapse," Cancer Discovery, vol. 7, no. 2, pp. 165-176, 2017.

[127] S. He and N. E. Sharpless, "Senescence in Health and Disease," Cell, vol. 169, no. 6, pp. 1000-1011, 2017.

[128] T. Saleh, L. Tyutyunyk-Massey, and D. A. Gewirtz, "Tumor cell escape from therapy-induced senescence as a model of disease recurrence after dormancy," Cancer Research, vol. 79, no. 6, pp. 1044-1046, 2019.

[129] K. Tominaga, "The emerging role of senescent cells in tissue homeostasis and pathophysiology," Pathobiology of Aging \& Age-related Diseases, vol. 5, no. 1, article 27743, 2015.

[130] A. Krtolica, S. Parrinello, S. Lockett, P. Y. Desprez, and J. Campisi, "Senescent fibroblasts promote epithelial cell growth and tumorigenesis: a link between cancer and aging," Proceedings of the National Academy of Sciences, vol. 98, no. 21, pp. 12072-12077, 2001.

[131] D. Liu and P. J. Hornsby, "Senescent human fibroblasts increase the early growth of xenograft tumors via matrix metalloproteinase secretion," Cancer Research, vol. 67, no. 7, pp. 3117-3126, 2007.

[132] R. M. Laberge, P. Awad, J. Campisi, and P. Y. Desprez, "Epithelial-mesenchymal transition induced by senescent fibroblasts," Cancer Microenvironment, vol. 5, no. 1, pp. 39-44, 2012.

[133] A. Glasauer and N. S. Chandel, "Targeting antioxidants for cancer therapy," Biochemical Pharmacology, vol. 92, no. 1, pp. 90-101, 2014.

[134] Y. Wang, H. Qi, Y. Liu et al., "The double-edged roles of ROS in cancer prevention and therapy," Theranostics, vol. 11, no. 10, pp. 4839-4857, 2021.

[135] C. K. Roberts and K. K. Sindhu, "Oxidative stress and metabolic syndrome,” Life Sciences, vol. 84, no. 21-22, pp. 705712, 2009.

[136] B. C. Dickinson and C. J. Chang, "Chemistry and biology of reactive oxygen species in signaling or stress responses," Nature Chemical Biology, vol. 7, no. 8, pp. 504-511, 2011.

[137] W. Yang, L. Zou, C. Huang, and Y. Lei, "Redox regulation of cancer metastasis: molecular signaling and therapeutic opportunities," Drug Development Research, vol. 75, no. 5, pp. 331-341, 2014.

[138] J. Krstić, D. Trivanović, S. Mojsilović, and J. F. Santibanez, "Transforming growth factor-beta and oxidative stress interplay: implications in tumorigenesis and cancer progression," Oxidative Medicine and Cellular Longevity, vol. 2015, 2015.

[139] D. Nikitovic, E. Corsini, D. Kouretas, A. Tsatsakis, and G. Tzanakakis, "ROS-major mediators of extracellular matrix remodeling during tumor progression," Food and Chemical Toxicology, vol. 61, pp. 178-186, 2013.

[140] E. Giannoni, M. Parri, and P. Chiarugi, "EMT and oxidative stress: a bidirectional interplay affecting tumor malignancy," Antioxidants \& Redox Signaling, vol. 16, no. 11, pp. 12481263, 2012.

[141] K. H. Krause, "Aging: a revisited theory based on free radicals generated by NOX family NADPH oxidases," Experimental Gerontology, vol. 42, no. 4, pp. 256-262, 2007.

[142] K. Bedard and K. H. Krause, "The NOX family of ROSgenerating NADPH oxidases: physiology and pathophysiology," Physiological Reviews, vol. 87, no. 1, pp. 245-313, 2007.
[143] G. Leonarduzzi, B. Sottero, G. Testa, F. Biasi, and G. Poli, "New insights into redox-modulated cell signaling," Current Pharmaceutical Design, vol. 17, no. 36, pp. 3994-4006, 2011.

[144] Y. Kitagishi and S. Matsuda, "Redox regulation of tumor suppressor PTEN in cancer and aging (review)," International Journal of Molecular Medicine, vol. 31, no. 3, pp. 511-515, 2013.

[145] J. F. Passos, G. Saretzki, and T. von Zglinicki, "DNA damage in telomeres and mitochondria during cellular senescence: is there a connection?," Nucleic Acids Research, vol. 35, no. 22, pp. 7505-7513, 2007.

[146] O. A. Sedelnikova, I. Horikawa, D. B. Zimonjic, N. C. Popescu, W. M. Bonner, and J. C. Barrett, "Senescing human cells and ageing mice accumulate DNA lesions with unrepairable double-strand breaks," Nature Cell Biology, vol. 6, no. 2, pp. 168-170, 2004.

[147] M. K. Kang, R. H. Kim, K. H. Shin, W. Zhong, K. F. Faull, and N. H. Park, "Senescence-associated decline in the intranuclear accumulation of hOGG1-alpha and impaired 8-oxo-dG repair activity in senescing normal human oral keratinocytes in vivo," Experimental Cell Research, vol. 310, no. 1, pp. 186195, 2005.

[148] H. A. Sawal, K. Asghar, M. Bureik, and N. Jalal, "Bystander signaling via oxidative metabolism," Oncotargets and Therapy, vol. 10, pp. 3925-3940, 2017.

[149] A. Laurent, C. Nicco, C. Chéreau et al., "Batteux F controlling tumor growth by modulating endogenous production of reactive oxygen species," Cancer Research, vol. 65, no. 3, pp. 948-956, 2005.

[150] J. M. DeSesso, "Cell death and free radicals: a mechanism for hydroxyurea teratogenesis," Medical Hypotheses, vol. 5, no. 9, pp. 937-951, 1979.

[151] J. M. DeSesso, “Amelioration of teratogenesis. I. Modification of hydroxyurea-induced teratogenesis by the antioxidant propyl gallate," Teratology, vol. 24, no. 1, pp. 19-35, 1981.

[152] K. Ziegler-Slylakakis, L. R. Schwarz, and U. Andrae, "Microsome- and hepatocyte-mediated mutagenicity of hydroxyurea and related aliphatic hydroxamic acids in V79 Chinese hamster cells," Mutation Research, vol. 152, no. 2-3, pp. 225-231, 1985.

[153] M. Lepoivre, J.-M. Flaman, P. Bobé, G. Lemaire, and Y. Henry, "Quenching of the tyrosyl free radical of ribonucleotide reductase by nitric oxide," The Journal of Biological Chemistry, vol. 269, pp. 21891-21897, 1994.

[154] C. M. Dong, X. L. Wang, G. M. Wang et al., "A stress-induced cellular aging model with postnatal neural stem cells," Cell Death \& Disease, vol. 5, no. 3, article e1116, 2017.

[155] Y. Zhai, R. Wei, J. Liu et al., "Drug-induced premature senescence model in human dental follicle stem cells," Oncotarget, vol. 8, no. 5, pp. 7276-7293, 2017.

[156] K. Geng, N. Fu, X. Yang, and W. Xia, “Adjudin delays cellular senescence through Sirt 3 mediated attenuation of ROS production," International Journal of Molecular Medicine, vol. 42, no. 6, pp. 3522-3529, 2014.

[157] J. L. Santos, P. L. Bosquesi, A. E. Almeida, C. M. Chin, and E. A. Varanda, "Mutagenic and genotoxic effect of hydroxyurea," International Journal of Biomedical Sciences, vol. 7, no. 4, pp. 263-267, 2011.

[158] T. Kühr, S. Burgstaller, U. Apfelbeck et al., “A randomized study comparing interferon (IFN $\alpha$ ) plus low-dose cytarabine and interferon plus hydroxyurea (HU) in early chronic-phase 
chronic myeloid leukemia (CML)," Leukemia Research, vol. 27, no. 5, pp. 405-411, 2003.

[159] J. I. Park, J. S. Jeong, J. Y. Han et al., "Hydroxyurea induces a senescence-like change of K562 human erythroleukemia cell," Journal of Cancer Research and Clinical Oncology, vol. 126, no. 8, pp. 455-460, 2000.

[160] J. C. Law, M. K. Ritke, J. C. Yalowich, G. H. Leder, and R. E. Ferrell, "Mutational inactivation of the p53 gene in the human erythroid leukemic K562 cell line," Leukemia Research, vol. 17, no. 12, pp. 1045-1050, 1993.

[161] S. H. Hong, B. Hong, D. C. Kim et al., "Involvement of mitogen-activated protein kinases and p21Waf1 in hydroxyurea- induced G1 arrest and senescence of McA-RH7777 rat hepatoma cell line," Experimental \& Molecular Medicine, vol. 36, no. 5, pp. 493-498, 2004.

[162] P. Liu, Z. Lu, Y. Wu et al., "Cellular Senescence-Inducing Small Molecules for Cancer Treatment," Current cancer drug targets, vol. 19, no. 2, pp. 109-119, 2019.

[163] T. Saleh, S. Bloukh, V. J. Carpenter et al., "Therapy-induced senescence: An "old" friend becomes the enemy," Cancers, vol. 12, no. 4, p. 822, 2020.

[164] T. Hirano, "IL-6 in inflammation, autoimmunity and cancer," International Immunology, vol. 33, no. 3, pp. 127-148, 2021.

[165] S. Roy Choudhury, S. Karmakar, N. L. Banik, and S. K. Ray, "Targeting angiogenesis for controlling neuroblastoma," Journal of Oncology, vol. 2012, Article ID 782020, 15 pages, 2012.

[166] E. J. Yeo, Y. C. Hwang, C. M. Kang et al., "Senescence-like changes induced by hydroxyurea in human diploid fibroblasts," Experimental Gerontology, vol. 35, no. 5, pp. 553$571,2000$.

[167] H. S. Kim, E. J. Yeo, S. H. Park et al., "p $21^{\text {WAF/CIP1/SDI1 }}$ is upregulated due to increased mRNA stability during hydroxyurea-induced senescence of human fibroblasts," Mechanisms of Ageing and Development, vol. 126, no. 12, pp. 1255-1261, 2005.

[168] E. Bodzak, M. D. Blough, P. W. K. Lee, and R. Hill, "p53 binding to the $\mathrm{p} 21$ promoter is dependent on the nature of DNA damage," Cell Cycle, vol. 7, no. 16, pp. 2535-2543, 2008.

[169] O. Yogev, S. Anzi, K. Inoue, and E. Shaulian, "Induction of transcriptionally active Jun proteins regulates drug-induced senescence," The Journal of Biological Chemistry, vol. 281, no. 45, pp. 34475-34483, 2006.

[170] M. C. Velarde, J. M. Flynn, N. U. Day, S. Melov, and J. Campisi, "Mitochondrial oxidative stress caused by Sod 2 deficiency promotes cellular senescence and aging phenotypes in the skin," Aging, vol. 4, pp. 3-12, 2012.

[171] C. Ding, X. Fan, and G. Wu, "Peroxiredoxin 1- an antioxidant enzyme in cancer," Journal of Cellular and Molecular Medicine, vol. 21, no. 1, pp. 193-202, 2017.

[172] J. Pawlowski and A. S. Kraft, "Bax-induced apoptotic cell death," Proceedings of the National Academy of Sciences, vol. 97, no. 2, pp. 529-531, 2000.

[173] S. Daniele, E. Da Pozzo, C. Iofrida, and C. Martini, "Human neural stem cell aging is counteracted by $\alpha$-glycerylphosphorylethanolamine," ACS Chemical Neuroscience, vol. 7, no. 7, pp. 952-963, 2016.

[174] S. Daniele, G. Mangano, L. Durando, L. Ragni, and C. Martini, "The nootropic drug A-glyceryl-phosphoryl-ethanolamine exerts neuroprotective effects in human hippo- campal cells," International Journal of Molecular Sciences, vol. 21, no. 3, p. 941, 2020.

[175] M. J. Morgan and Z. G. Liu, "Crosstalk of reactive oxygen species and NF- $\kappa$ B signaling," Cell Research, vol. 21, no. 1, pp. 103-115, 2011.

[176] M. Dominici, K. le Blanc, I. Mueller et al., "Minimal criteria for defining multipotent mesenchymal stromal cells. The International Society for Cellular Therapy position statement," Cytotherapy, vol. 8, no. 4, pp. 315-317, 2006.

[177] M. F. Pittenger, A. M. Mackay, S. C. Beck et al., "Multilineage potential of adult human mesenchymal stem cells," Science, vol. 284, no. 5411, pp. 143-147, 1999.

[178] F. Cammarota and M. O. Laukkanen, "Mesenchymal stem/stromal cells in stromal evolution and cancer progression," Stem Cells International, vol. 2016, 2016.

[179] M. D. Castellone, L. E. Laatikainen, J. P. Laurila et al., "Brief report: mesenchymal stromal cell atrophy in coculture increases aggressiveness of transformed cells," Stem Cells, vol. 31, no. 6, pp. 1218-1223, 2013.

[180] S. Bjelica, M. Diklić, D. Đikić et al., "Hydroxyurea-induced senescent peripheral blood mesenchymal stromal cells inhibit bystander cell proliferation of JAK2V617F-positive human erythroleukemia cells," The FEBS Journal, vol. 286, no. 18, pp. 3647-3663, 2019.

[181] D. B. Lombard, F. W. Alt, H. L. Cheng et al., "Mammalian Sir 2 homolog SIRT3 regulates global mitochondrial lysine acetylation," Molecular and Cellular Biology, vol. 27, no. 24, pp. 8807-8814, 2007.

[182] P. Maissan, E. Mooij, and M. Barberis, "Sirtuins-mediated system-level regulation of mammalian tissues at the interface between metabolism and cell cycle: a systematic review," Biology, vol. 10, no. 3, p. 194, 2021.

[183] Y. Chen, J. Zhang, Y. Lin et al., "Tumour suppressor SIRT3 deacetylates and activates manganese superoxide dismutase to scavenge ROS," EMBO Reports, vol. 12, no. 6, pp. 534$541,2011$.

[184] W. Xia and K. Geng, "A sirtuin activator and an antiinflammatory molecule-multifaceted roles of adjudin and its potential applications for aging-related diseases," Seminars in Cell \& Developmental Biology, vol. 59, pp. 71-78, 2016.

[185] M. S. Park, J. S. Choi, W. Lee et al., "Pharmacogenomic analysis indicates potential of 1, 5-isoquinolinediol as a universal anti-aging agent for different tissues," Oncotarget, vol. 6, no. 19, pp. 17251-17260, 2015.

[186] D. M. Boesten, J. M. J. de Vos-Houben, L. Timmermans, G. J. M. den Hartog, A. Bast, and G. J. Hageman, "Accelerated aging during chronic oxidative stress: a role for PARP-1," Oxidative Medicine and Cellular Longevity, vol. 2013, Article ID 680414, 10 pages, 2013.

[187] A. Mangerich and A. Bürkle, "Pleiotropic cellular functions of PARP1 in longevity and aging: genome maintenance meets inflammation," Oxidative Medicine and Cellular Longevity, vol. 2012, Article ID 321653, 19 pages, 2012.

[188] S. Wang, A. Prizment, B. Thyagarajan, and A. Blaes, "Cancer treatment-induced accelerated aging in cancer survivors: biology and assessment," Cancers (Basel), vol. 13, no. 3, p. 427, 2021.

[189] D. R. Hodge, B. Peng, C. Pompeia et al., "Epigenetic silencing of manganese superoxide dismutase (SOD-2) in KAS 6/1 human multiple myeloma cells increases cell proliferation," Cancer Biology \& Therapy, vol. 4, no. 5, pp. 585-592, 2005. 
[190] G. D. Pule, S. Mowla, N. Novitzky, C. S. Wiysonge, and A. Wonkam, "A systematic review of known mechanisms of hydroxyurea-induced fetal hemoglobin for treatment of sickle cell disease," Expert Review of Hematology, vol. 8, no. 5, pp. 669-679, 2015.

[191] J. Mikuła-Pietrasik, A. Niklas, P. Uruski, A. Tykarski, and K. Książek, "Mechanisms and significance of therapyinduced and spontaneous senescence of cancer cells," Cellular and molecular life sciences: CMLS, vol. 77, no. 2, pp. 213-229, 2020.

[192] B. Perillo, M. di Donato, A. Pezone et al., "ROS in cancer therapy: the bright side of the moon," Experimental \& Molecular Medicine, vol. 52, no. 2, pp. 192-203, 2020. 